\title{
Registro regional de fechas radiocarbónicas del norte de Chile
}

LAUTARo NúÑEZ A. ${ }^{1}$

\section{Introducción}

En estos últimos años la disciplina arqueológica en los Andes se ha beneficiado con la aplicación de métodos complejos que suponen una participación activa en el proceso de reevaluación y crítica de las metodologías tradicionales. Sin embargo, pese a este esfuerzo, es muy poco cuanto sabemos sobre la real naturaleza cronológica de las poblaciones prehistóricas en los Andes Meridionales. Este artículo reúne la información básica y tiende a ordenar y evaluar 69 muestras radiocarbónicas registradas en el norte de Chile (regiones I y II) (Cuadros 1 y 2). Para esto, analizamos cada fecha por separado y al final hacemos un breve comentario con un cuadro cronológico absoluto, construido en términos operacionales.

Registros de fechas:

\section{Muestra 1}

Sitio: Quitor 6.

Ubicación: Localidad de Quitor, en el área de San Pedro de Atacama.

Subárea ecológica: Oasis al pie de la Puna de Atacama.

Tipo de sitio: Cementerio.

Tipo de muestra: Fragmento de madera (poste señalizador de tumba).

Localización en el sitio: Tumba colectiva $\mathrm{N}^{\mathrm{o}} 2532$.

Nombre del laboratorio: Comisariado de Energía Atómica, Saclay, Francia.

1 Museo Arqueológico de San Pedro de Atacama, Universidad del Norte, CHILE.
Colector de la muestra: G. Le Paige, Museo Arqueológico de San Pedro de Atacama, Universidad del Norte.

Sigla y número de laboratorio: Sa-226.

Resultado recibido: Edad absoluta: $1700 \pm 150$ años AP.

Edad calendario: $250 \pm 150$ años DC.

Contexto diagnóstico fechado: Cerámica San Pedro Negro Pulido (fase San Pedro II).

Comentario: La fecha fue criticada, por cuanto en la fase San Pedro II se asocian componentes Tiwanaku Clásico y Expansivo, presumiendo que la datación recibida era muy temprana. Sin embargo, nuevas fechas para la cerámica Negra Pulida confirman esta datación temprana. De modo que los ingredientes Tiwanaku asociados a Negra Pulida deben considerarse algo más tempranas a las determinaciones conocidas.

Referencias bibliográficas: Le Paige (1963a, 1963b, 1964), Orellana (1963), Núñez y Varela (1966), Gordon (1967).

Addenda: "Este fechado (Las Cuevas) cercano a San Antonio de los Cobres, dio 200 DC. Se trata de un basural donde hay una gran homogeneidad en los tipos cerámicos. Hay dos tipos que se presentan en una gran popularidad: Negra Pulida y Roja Pulida. Creo que son similares a su cerámica de San Pedro de Atacama. También hay Negro Grabado y tres fragmentos unguicular, imbricado y corrugado. Lo importante de todo ello es que concuerda con sus dos fechas de 250 y $300 \mathrm{DC}$, fechados que siempre me parecieron excelentes" (E. Cigliano com. pers. a G. Le Paige, agosto 2 de 1968). 


\section{Muestra 2}

Sitio: Solor 6.

Ubicación: Localidad de Solor, en el área de San Pedro de Atacama.

Subárea ecológica: Oasis al pie de la Puna de Atacama.

Tipo de sitio: Cementerio.

Tipo de muestra: Madera (fragmento de tronco).

Localización en el sitio: Capa aluvial entre dos niveles de tumbas.

Nombre del Laboratorio: Comisariado de Energía Atómica, Saclay, Francia.

Colector de la muestra: G. Le Paige (antes de 1963), Museo Arqueológico de San Pedro de Atacama, Universidad del Norte.

Sigla y número del Laboratorio: Sa-109.

Resultado recibido: Edad absoluta: $1650 \pm 150$ años AP (anterior a 1950).

Edad calendario: $300 \pm 150$ años DC.

Contexto diagnóstico fechado: A pesar de las confusiones en términos de asociación cultural (Le Paige 1964) y las reevaluaciones posteriores que ha recibido esta fecha, podría servir para fechar tiestos negros pulidos, clásicos de la fase II del Complejo San Pedro.

Comentario: Hay críticas a la metodología del muestreo, por cuanto los restos orgánicos se obtuvieron de una capa aluvional, creando dificultad para relacionarla a las urnas subyacentes y/o las evidencias funerarias ubicadas en el nivel superior.

Referencias bibliográficas: Ver ficha $\mathrm{N}^{\mathrm{o}} 1$.

\section{Muestra 3}

Sitio: Quiani.

Ubicación: I región, localidad de Arica, sector Quiani, $3 \mathrm{~km}$ al sur de Playa Miller (18³2' Lat. S; $70^{\circ} 20^{\prime}$ Long. O).
Subárea ecológica: Zona de eficiencia de desembocadura de ríos en la costa de Arica (fricción entre subárea Valles Transversales Norte y subárea Marítima Norte).

Tipo de sitio: Basural.

Tipo de muestra: Carbón vegetal (6 gr), restos carbonizados de huesos de pescados y pájaros (3 gr), cenizas (9 gr).

Localización en el sitio: Fogón en la base o comienzo del basural.

Nombre del laboratorio: Isotopos Inc., Estados Unidos.

Colector de la muestra: G. Mostny (1963), Museo Nacional de Historia Natural, Santiago.

Sigla y número del laboratorio: I-1348.

Resultado recibido: Edad absoluta: $6170 \pm 220$ años AP.

Edad calendario: 4220 \pm 220 años AC.

Contexto diagnóstico fechado: "Está fuera de toda discusión que la muestra 1 está relacionada con la Cultura del Anzuelo de Concha; aun cuando el estrato del que se obtuvieron los artefactos característicos de este período es muy delgado, de la descripción de la Dra. Mostny se juzga que la muestra está relacionada con parte superior del estrato, y que por lo tanto esta muestra puede ser considerada como del final del período del sitio de Quiani” (Bird 1967).

"No podemos establecer que la muestra indica el comienzo del segundo período cultural, debido a que la capa intermedia es casi estéril, pero no lo es completamente. Sin embargo, es muy anterior a las bolas que aparecen en la última fase del período" (J. Bird com. pers. a R. Gordon, 1967).

Comentario: Fecha coherente para la primera ocupación costera preagrícola correspondiente a la llamada "Cultura del Anzuelo de Concha".

Referencias bibliográficas: Bird (1943, 1946, 1967), Mostny (1964), Núñez y Varela (1966), Gordon (1967). 


\section{Muestra 4}

Sitio: Quiani II.

Ubicación: I región, localidad de Arica, sector Quiani, $3 \mathrm{~km}$ al sur de Playa Miller.

Subárea ecológica: Zona de eficiencia de desembocaduras de ríos en la costa de Arica. Fricción entre la subárea de Valles Transversales Norte y subárea Marítima Norte.

Tipo de sitio: Basural.

Tipo de muestra: Carbón de madera (6.5 gr), huesos de pescados carbonizados ( 3 gr)

Localización en el sitio: Capa arenosa de $30 \mathrm{~cm}$ en un nivel más superior al estrato fechado con la muestra temprana, de la misma columna estratigráfica.

Nombre del laboratorio: Isotopos Inc., Estados Unidos.

Colector de la muestra: G. Mostny (1963), Museo Nacional de Historia Natural, Santiago.

Sigla y número del laboratorio: I-1349.

Resultado recibido: Edad absoluta: 5630 \pm 145 años AP.

Edad calendario: $3680 \pm 145$ años AC.

Contexto diagnóstico fechado: Contexto de la estratificación final de la llamada "Cultura del Anzuelo de Concha" (boleadoras para pájaros, doble punta $\mathrm{y}$ anzuelos de quisco).

Comentario: "Estadísticamente este es un argumento razonable para no atribuir la muestra 2 de radiocarbono a algunas de las fases últimas del Período del Anzuelo de Concha" (Bird 1967).

"En resumen, de la observación de la muestra 2, creo que su asociación cultural es equivalente a alguna porción del estrato 1 de la excavación efectuada en 1941, en Pichalo. Ella fue elaborada, a pesar de la falta de artefactos directamente asociados, como una prueba de validez de la muestra 1" (Bird 1967).

Referencias bibliográficas: Ver ficha $\mathrm{N}^{\circ} 3$.

\section{Muestra 5}

Sitio: Guatacondo I.

Ubicación: I región, localidad de Tamentica, curso inferior de la quebrada de Guatacondo.

Subárea ecológica: Quebrada en contacto con Pampa del Tamarugal (Valles Transversales Norte).

Tipo de sitio: Aldea.

Tipo de muestra: Madera (chañar).

Localización en el sitio: Poste asociado al recinto 12.

Nombre del laboratorio: Instituto Venezolano de Investigaciones Científicas.

Colector de la muestra: G. Mostny (1964), Museo Nacional de Historia Natural, Santiago.

Sigla y número del laboratorio: IVIC-166.

Resultado recibido: Edad absoluta: $1890 \pm 90$ años AP.

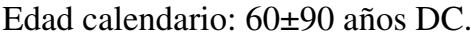

Contexto diagnóstico fechado: La muestra fecharía el tiempo de la construcción de una parte de la aldea. Marcaría el comienzo de la ocupación (?). La fecha resulta coherente para varios especialistas. Fecha un establecimiento aldeano temprano.

Comentario: La aldea de Guatacondo posee un patrón de poblamiento similar a las evidencias altiplánicas tempranas, a base de recintos circulares aglutinados con un patio central. Los pisos de las habitaciones excavadas señalan la presencia de agricultura temprana con maíz, zapallos y porotos, incluyendo un fuerte énfasis en la recolección de vainas de prosopis. Las informaciones contextuales detalladas están en proceso de estudio.

Referencias bibliográficas: Mostny (1965), Núñez y Varela (1966), Meighan (1970), P. Núñez (Ms). 


\section{Muestra 6}

Sitio: Guatacondo I.

Ubicación: I región, localidad de Tamentica, sector inferior de la quebrada de Guatacondo.

Subárea ecológica: Quebrada en contacto con Pampa del Tamarugal (subárea Valles Transversales Norte).

Tipo de sitio: Aldea.

Tipo de muestra: Mazorca de maíz.

Localización en el sitio: Bodega o pequeño depósito subterráneo en el recinto 12 .

Nombre del laboratorio: Instituto Venezolano de Investigaciones Científicas.

Colector de la muestra: G. Mostny (1964), Museo Nacional de Historia Natural, Santiago.

Sigla y número del laboratorio: IVIC-167.

Resultado recibido: Edad absoluta: $1175 \pm 90$ años AP.

Edad calendario: 775 \pm 90 años DC.

Contexto diagnóstico fechado: Posible reocupación tardía de un recinto habitacional de la aldea Guatacondo. No hay artefactos o rasgos culturales específicos vinculados con la fecha.

Comentario: "Parece improbable que la cosecha haya sido depositada 715 años después de la construcción del recinto" (Mostny 1965). Ver problema de muestras de maíz en la ficha $\mathrm{N}^{\circ} 10$ de Pica 8.

Referencia bibliográfica: Mostny (1965).

\section{Muestra 7}

Sitio: Guatacondo I.

Ubicación: I región, localidad de Tamentica, sector inferior de la quebrada de Guatacondo.
Subárea ecológica: Quebrada en contacto con Pampa del Tamarugal (Subárea Valles Trasversales Norte).

Tipo de sitio: Aldea.

Tipo de muestra: Carbón de madera, en el sector del recinto 12 .

Localización en el sitio: Sector del recinto 12: "El carbón fue encontrado en un hogar, cerca de la parte SO del muro del mismo recinto, aproximadamente $0.5 \mathrm{~m}$ sobre el piso original de la habitación y unos 0.2-0.3 m encima de una capa de ramillas" (Mostny 1965).

Nombre del laboratorio: Instituto Venezolano de Investigaciones Científicas.

Colector de la muestra: G. Mostny (1964), Museo Nacional de Historia Natural, Santiago.

Sigla y número del laboratorio: IVIC-168.

Resultado recibido: Edad absoluta: $775 \pm 160$ años AP.

Edad calendario: 1175 \pm 160 años DC.

Contexto diagnóstico fechado: Según Mostny (1965), corresponde a una reocupación secundaria.

Comentario: "El intervalo de 715 años entre la construcción de la habitación (IVIC-166) y las mazorcas de maíz (IVIC-167) es demasiado largo. Empero, no disponemos de mejor medio para determinar cuál de las dos fechas es aplicable" (Mostny en Tamers 1965).

Mostny (1965) informó que esta fecha pertenece a un momento en que el recinto estaba en ruinas, debido a que la muestra se obtuvo inmediatamente sobre el techo ("ramillas") caído.

Referencia bibliográfica: Mostny (1965).

\section{Muestra 8}

Sitio: Pisagua Viejo 4. 
Ubicación: I región, localidad puerto de Pisagua. Terraza sur desembocadura del río Camiña (Pisagua Viejo), 19³3' Lat. S; 70 14' Long. O.

Subárea ecológica: Zona de eficiencia de desembocadura de río (subárea Marítima Norte).

Tipo de sitio: Cementerio.

Tipo de muestra: Madera y fibra vegetal.

Localización en el sitio: Tumba $\mathrm{N}^{\circ} 2$ (relleno de momificación artificial en el interior del tórax).

Nombre del laboratorio: Instituto Venezolano de Investigaciones Científicas.

Colector de la muestra: L. Núñez (1963), Universidad de Chile, Antofagasta-Iquique.

Sigla y número del laboratorio: IVIC-170.

Resultado calculado: Anterior a nuestra era.

Resultado recibido: Edad absoluta: $4880 \pm 320$ y $5220 \pm 170$ años AP.

Edad calendario: 3050 \pm 245 años AC (promedio).

Observación del laboratorio: El peso considerable de la muestra dio lugar a una determinación doble para asegurar una fecha correcta. Ambas determinaciones son muy coherentes y el promedio resultante parece ser lógico.

Contexto diagnóstico fechado: La fecha sitúa temporalmente a un enterramiento colectivo de cuerpos extendidos con mascarillas faciales y las típicas preparaciones o momificaciones artificiales (Período "Aborígenes de Arica" de Uhle, 1919). La excavación de prueba no ofreció rasgos culturales diagnósticos, pero el peculiar sistema de preparación funeraria identifica el Complejo Chinchorro en una posible fase temprana.

Referencias bibliográficas: Uhle (1919), L. Núñez (Ms).

\section{Muestra 9}

Sitio: Dupont 1.

Ubicación: II región, localidad de Calama, sector Industria de Explosivos Ex Dupont (22 28' Lat. S; 68 58' Long O).

Subárea ecológica: Valle Medio del río Loa, componente de la subárea de Valles Transversales Norte.

Tipo de sitio: Cementerio.

Tipo de muestra: Textil.

Localización en el sitio: Enterramiento $\mathrm{N}^{\mathrm{o}} 1$ (parte del contexto funerario).

Nombre del laboratorio: Instituto Venezolano de Investigaciones Científicas.

Colector de la muestra: L. Núñez (1964), Universidad de Chile, Antofagasta-Iquique.

Sigla y número del laboratorio: IVIC-171.

Resultado calculado: Período Tardío (1000-1500 años DC).

Resultado recibido: Edad absoluta: 460 \pm 100 años AP.

Edad calendario: $1490 \pm 100$ años DC. Equivale a $1390 \pm 100$ DC

Contexto diagnóstico fechado: La muestra fecha un sector no alterado del cementerio tardío ubicado junto al río Loa. Este sector se caracteriza por contextos típicamente tardíos con presencia predominante de cerámica Dupont (pucos con interior negro pulido, exterior café alisado mal tratado) y artefactos insuflatorios asociados.

Comentario: De acuerdo a los rasgos tardíos inmediatamente preinca se aplicó el sigma con valor menor, arrojando el equivalente coherente de 1390 años DC.

Referencia bibliográfica: L. Núñez (Ms-a). 


\section{Muestra 10}

Sitio: Pica 8.

Ubicación: I región, localidad de Matilla, valle de Quisma (20 31' Lat. S; 69 32’ Long. O).

Subárea ecológica: Oasis piemontanos (oasis y valles al oriente de Pampa del Tamarugal), componentes de la subárea Valles Transversales Norte.

Tipo de sitio: Cementerio.

Tipo de muestra: Mazorca de maíz.

Localización en el sitio: Tumba $N^{\circ}$ 6, Sección A.

Nombre del laboratorio: Instituto Venezolano de Investigaciones Científicas.

Colector de la muestra: L. Núñez (1964), Universidad de Chile, Antofagasta-Iquique.

Sigla y número del laboratorio: IVIC-172.

Resultado calculado: Período Tardío (1000-1500 años DC).

Resultado recibido: Edad absoluta: $310 \pm 110$ años AP.

Edad calendario: $1640 \pm 110$ años DC.

Observación del laboratorio: Ver comentario adjunto.

Contexto diagnóstico fechado: Iguales a los de la muestra 11 (Complejo Pica).

Comentario: Esta fecha cae en un tiempo colonialespañol, lo cual contradice la evidencia arqueológica evidentemente preinca. Nótese que la fecha coherente $\mathrm{N}^{\mathrm{o}} 11$ proviene de la misma tumba colectiva. Sea cual fuere la causa de la alteración temporal dada por las fechas en maíces, lo básico es que la muestra 11 representa bien el momento tardío inmediatamente preinca, de acuerdo a los análisis culturales.

Sobre esta situación anormal, el Dr. Tamers entregó una información básica en carta a G. Mostny (abril 22 de 1965).
"Al finalizar la determinación de tres muestras más de Chile en nuestro laboratorio del IVIC, los resultados arrojados son los siguientes:

\section{IVIC}

172 (Pica 5, mazorcas de maíz, plantas) 310 \pm 110 años anteriores a 1950.

173 (Pica 6, tejido) 930 \pm 90 años anteriores a 1950.

174 (Pica 7, mazorcas de maíz) 220 \pm 80 años anteriores a 1950.

Las diferencias que existen entre las edades de las muestras son sorprendentes y aparentemente hay serios desacuerdos en la evidencia arqueológica de las muestras IVIC-172 y 174. No obstante, estamos seguros que no hubo error de procedimiento en nuestro laboratorio, así como tampoco hay posibilidad de que se hayan mezclado las muestras aquí en el IVIC. Mi opinión es que las fechas incorrectas para IVIC-172 y 174 se deben a lo que hemos observado en muestras de edades conocidas de alrededor de 700 años de edad. Esto es, que parece ser que ocurrió algún efecto natural durante ese período que aumentó considerablemente la cantidad de depósito de $\mathrm{C}^{14}$ proveniente de la atmósfera. Una explicación a esto podría ser una variación en el flujo de rayos cósmicos sobre la Tierra. El resultado neto es que frecuentemente las muestras de ese período presentan contenidos de $\mathrm{C}^{14}$ del orden del 5\% de exceso del que deberían tener. Esto es suficiente para explicar la discrepancia entre las tres fechas mencionadas arriba.

Hasta hace poco este efecto se había notado solamente en las muestras provenientes del hemisferio norte, sin embargo, hemos notado esto mismo en un trozo de tela precolombina proveniente de Perú. Es muy importante para nuestro entendimiento final sobre el proceso responsable de estas variaciones en la cantidad de depósito de $\mathrm{C}^{14}$ el hecho de que estamos observando efectos similares en el hemisferio sur. Esta es la razón por la cual estamos interesados en ponernos en contacto con un experto en "anillos de árboles" en Chile o Argentina con el objeto de obtener una serie de muestras de edades conocidas".

Sobre la problemática específica del maíz, hay estudios en marcha bien conducidos por el Dr. Lerman, de la Universidad de Groningen, quien gentilmente nos ha informado que: "tal como lo comenté en el $38^{\circ}$ Congreso de Americanistas, creo que la mejor 
fecha es la del maíz, una vez corregida por variaciones seculares y por fraccionamientos isotópicos. Así se obtiene algo como 1340 DC y 1470 DC para el maíz. Y para el textil ca. 1040-1240 DC (observe que el maíz resulta unos 300 años más viejo" (com. pers., marzo 1 de 1969).

Si las cifras son así correctas, no habría alteración alguna. El cuerpo con el contexto fechado (textil) correspondería a los primeros enterramientos en la tumba colectiva y eventualmente la tumba con el maíz se ubicaría al final del desarrollo tardío. A grandes rasgos, el denso cementerio Pica 8 podría perfectamente marcar hitos que van desde 1000 a 1500 años DC. Quinientos años de desarrollo del cementerio es un tiempo acorde a las evidencias regionales. Pero como medida precautiva, la fecha del textil servirá de base para cronologizar el hipotético comienzo del desarrollo del Complejo Pica.

Referencia bibliográfica: L. Núñez (Ms-b).

\section{Muestra 11}

Sitio: Pica 8.

Ubicación: I región, localidad de Matilla, valle de Quisma (2031' Lat. S; 69 32' Long. O).

Subárea ecológica: Oasis piemontanos (oasis y valles al oriente de Pampa del Tamarugal), componentes de la subárea Valles Transversales Norte.

Tipo de sitio: Cementerio.

Tipo de muestra: Textil (lana de camélido).

Localización en el sitio: Tumba 6, Sección A.

Nombre del laboratorio: Instituto Venezolano de Investigaciones Científicas.

Colector de la muestra: L. Núñez (1964), Universidad de Chile, Antofagasta-Iquique.

Sigla y número del laboratorio: IVIC-173.

Resultado calculado: Período Tardío (1000-1500 años DC).

Resultado recibido: Edad absoluta: 930 \pm 90 años AP.
Edad calendario: $1020 \pm 90$ años DC.

Observación del laboratorio: Hay acuerdo en que esta muestra textil es la más adecuada del total de las tres procesadas.

Contexto diagnóstico fechado: Tumba colectiva tipo "pirca" correspondiente a un rasgo funerario minoritario del Complejo Pica. Sin embargo, los contextos culturales son los que profusamente caracterizan al Complejo.

Comentario: Fecha coherente, utilizada como un eventual comienzo de la consolidación del campesinado en los oasis piqueños. Los contextos de la secuencia de los oasis Pica-Matilla están en proceso de estudio. Algunas observaciones se señalan en las referencias bibliográficas. A grandes rasgos se trata de una población contemporánea a la expansión San Miguel, con una relación altiplánica dependiente y acceso a otras subáreas ecológicas aledañas incluyendo la costa.

Referencia bibliográfica: L. Núñez (Ms-b).

\section{Muestra 12}

Sitio: Pica 8.

Ubicación: I región, localidad de Matilla, valle de Quisma (20 31' Lat. S; 69 32' Long. O).

Subárea ecológica: Oasis piemontanos (oasis y valles piemontanos al oriente de Pampa del Tamarugal), componentes de la subárea Valles Transversales Norte.

Tipo de sitio: Cementerio.

Tipo de muestra: Mazorcas de maíz.

Localización en el sitio: Tumba 30, Sección B.

Nombre del laboratorio: Instituto Venezolano de Investigaciones Científicas.

Colector de la muestra: L. Núñez (1964), Universidad de Chile, Antofagasta-Iquique.

Sigla y número del laboratorio: IVIC-174.

Resultado calculado: Período Tardío (1000-1500 años DC). 
Resultado recibido: Edad absoluta: $220 \pm 80$ años AP.

Edad calendario: $1730 \pm 80$ años DC.

Observación del laboratorio: Fecha dudosa.

Contexto diagnóstico fechado: Cerámica tardía preinca (Chilpe). En general, la muestra se asocia a artefactos típicos del Complejo Pica.

Comentario: De nuevo aquí se da el caso de una muestra de maíz que resulta colonial española, en contradicción con la evidencia arqueológica. Esta anormalidad repetida en otra tumba diferente a la colectiva pircada $\mathrm{N}^{\circ} 6$, abre serias sospechas que por ahora deben inhibir futuros muestreos de esta naturaleza.

Referencias bibliográficas: Ver observaciones anteriores.

\section{Muestra 13}

\section{Sitio: Conanoxa W(a).}

Ubicación: I región, localidad Camarones, terraza del sector Conanoxa (19 $02^{\prime}$ Lat. S; 69 59' Long. O).

Subárea ecológica: Valle inferior (subárea Valles Transversales Norte) con desagüe al Pacífico.

Tipo de sitio: Campamento.

Tipo de muestra: Deposiciones de herbívoro no identificado (?).

Localización en el sitio: "La muestra se obtuvo del estrato que cubría la estructura 1 del sitio Cxa $\mathrm{W}$ (a) y, por consiguiente, fecha el final de la ocupación del sitio" (Schiappacasse y Niemeyer 1969).

Nombre del laboratorio: Instituto Venezolano de Investigaciones Científicas.

Colectores de la muestra: H. Niemeyer y V. Schiappacasse, Museo Nacional de Historia Natural, Academia Chilena de Ciencias Naturales.

Sigla y número del laboratorio: IVIC-175.
Resultado recibido: Edad absoluta: $3740 \pm 130$ años AP.

Edad calendario: $1790 \pm 130$ años AC.

Contexto diagnóstico fechado: Industria lítica y asociados vinculados con ambientes marítimos e internos. Se incluyen morteros y fauna marítima y terrestre. Hay informe detallado (Niemeyer y Schiappacasse 1963).

Comentario: "Sitios precerámicos conforman una cultura de recolectores-cazadores trashumantes, cuyos caracteres distintivos permitieron ubicarla en las postrimerías del período preagrícola del norte de Chile" (Schiappacasse y Niemeyer 1969).

\section{Muestra 14}

Sitio: Conanoxa E-1.

Ubicación: I región. Localidad Camarones, terraza del sector Conanoxa (19 $02^{\prime}$ Lat. S; 69 59' Long. O).

Subárea ecológica: Valle inferior (subárea Valles Transversales Norte), con desagüe al Pacífico.

Tipo de sitio: Estructuras habitacionales.

Tipo de muestra: Carbón vegetal.

Localización en el sitio: Bolsón con carbón vegetal en el piso de la habitación A.

Nombre del laboratorio: Instituto Venezolano de Investigaciones Científicas.

Colectores de la muestra: H. Niemeyer y V. Schiappacasse, Museo Nacional de Ciencias Naturales, Academia Chilena de Ciencias Naturales.

Sigla y número del laboratorio: IVIC-176.

Resultado recibido: Edad absoluta: $1150 \pm 95$ años AP.

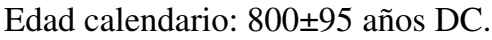

Contexto diagnóstico fechado: Ocupación en habitaciones vinculadas con trabajos agrícolas pretardíos: maíz, porotos, calabazas y posible algodón. 
Comentario: Se trata de una de las primeras fechas que relacionan estructuras habitacionales con evidencias agrícolas pretardías.

Referencias bibliográficas: Niemeyer y Schiappacasse (1963), Schiappacasse y Niemeyer (1969).

\section{Muestra 15}

Sitio: Conanoxa E-6.

Ubicación: I región, localidad Camarones, terraza del sector Conanoxa (19 ${ }^{\circ} 59^{\prime}$ Lat. S; 69 59' Long. O).

Subárea ecológica: Valle inferior (subárea Valles Transversales Norte), con desagüe al Pacífico.

Tipo de sitio: Cementerio (túmulos).

Tipo de muestra: Textil (lana de camélido).

Localización en el sitio: Tumba E.

Nombre del laboratorio: Instituto Venezolano de Investigaciones Científicas.

Colectores de la muestra: H. Niemeyer y V. Schiappacasse, Museo Nacional de Historia Natural, Academia Chilena de Ciencias Naturales.

Sigla y número de laboratorio: IVIC-344.

Resultado recibido: Edad absoluta: $2270 \pm 70$ años AP.

Edad calendario: $320 \pm 70$ años AC.

Contexto diagnóstico fechado: La fecha sitúa rasgos característicos para las poblaciones del Período Temprano pretiwanaku con utilización de cerámica y maíz. La relación se establece con similares poblaciones agrícolas tempranas revisadas recientemente (L. Núñez 1971).

Comentario: "El cementerio de túmulos Cxa E-6 había sido asimilado originalmente, al mismo complejo cultural representado en los sitios de vivienda, por la ausencia de elementos diferenciales suficientes, pero haciendo notar que el cementerio poseía semejanzas básicas con otros cementerios de túmulos descritos por Alvarez en Cerro Sombrero y
Las Riveras, ambos en el valle de Azapa, y también con el Complejo Faldas del Morro identificado por Dauelsberg (1963) en Arica" (Schiappacasse y Niemeyer 1969).

Referencias bibliográficas: Ver ficha anterior.

\section{Muestra 16}

Sitio: San Lorenzo.

Ubicación: II región, localidad Tulan (23 15’ Lat. S; $67^{\circ} 25^{\prime}$ Long. O).

Subárea ecológica: Borde oriental de la cinta de oasis del desierto de Atacama, pie occidental de la Puna de Atacama.

Tipo de sitio: Cueva.

Tipo de muestra: Carbón.

Localización en el sitio: Fogón (no hay datos estratigráficos).

Nombre del laboratorio: Hannover Radiocarbon.

Colector de la muestra: J. C. Spahny (1962), Museo de Ginebra.

Sigla y número del laboratorio: HV-299.

Resultado recibido: Edad absoluta: $10280 \pm 120$ años AP.

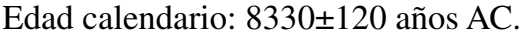

Contexto diagnóstico fechado: Insegura relación con pinturas rupestres ubicadas en el sitio. No hay datos relacionados a contextos culturales específicos.

"Comentario: Cueva con pinturas de ceremonias de caza con danzarines, pertenecientes a una fase precerámica" (Hannover Radiocarbon Measurements IV).

Tanto la muestra HV-298 como HV-299 demuestran el interés de Spahny por fechar evidencias de pinturas rupestres ubicadas en cuevas. Desgraciadamente no hay informes que aseguren una relación entre las pictografías y las evidencias estratigráficas concretas. 
En el caso de la muestra HV-299, aunque no tenga ninguna implicancia tipológica en términos de contextos culturales asociados, debe evaluarse por tratarse de la fecha más temprana del área y que al situarse en una zona con notables evidencias de caza-recolección preagrícola podría sugerir pautas a futuras investigaciones.

Referencia bibliográfica: Hannover Radiocarbon Measurements IV (Radiocarbon 9, 1967).

\section{Muestra 17}

Sitio: Tulan.

Ubicación: II región, localidad Tulan, borde oriental de la cinta de oasis del Desierto de Atacama (23 ${ }^{\circ}$ $48^{\prime}$ Lat. S; $68^{\circ} 2^{\prime}$ ' Long. O).

Subárea ecológica: Borde oriental de cinta de oasis del desierto de Atacama, pie de la Puna de Atacama.

Tipo de sitio: Cueva (cerca de Tulan).

Tipo de muestra: Carbón.

Localización en el sitio: Posiblemente se obtuvo de algún depósito no reportado, del interior de la cueva. No hay datos concretos.

Nombre del laboratorio: Hannover Radiocarbon.

Colector de la muestra: J. C. Spahny, Museo de Ginebra.

Sigla y número del laboratorio: HV-298.

Resultado recibido: Edad absoluta: $1180 \pm 60$ años AP.

Edad calendario: 770 \pm 60 años DC.

Contexto diagnóstico fechado: Insegura relación con pinturas rupestres ubicadas en el sitio.

Comentario: "Pinturas en una cueva con hombres y camélidos y abundantes símbolos geométricos; la fecha apunta el tiempo de la cultura atacameña hacia el siglo X de nuestra era (mayor desarrollo)" (Hannover Radiocarbon Measurements IV).

No hay un informe explícito sobre el real significado de esta fecha por parte del investigador colector de la muestra.

Referencia bibliográfica: Hannover Radiocarbon Measurements (Radiocarbon 9).

\section{Muestra 18}

Sitio: Azapa 8.

Ubicación: I región, localidad San Miguel de Azapa, valle de Azapa, cerca del puerto de Arica.

Subárea ecológica: Valle interior en contacto con el Pacífico (subárea Valles Transversales Norte).

Tipo de sitio: Cementerio.

Tipo de muestra: Tejido de fibra vegetal.

Localización en el sitio: Enterramiento M-42.

Nombre del laboratorio: UCLA Radiocarbon.

Colector de la muestra: O. Espoueys (1965), Centro de Antropología de Arica.

Sigla y número del laboratorio: UCLA 1294 D.

Resultado recibido: Edad absoluta: $810 \pm 80$ años AP.

Edad calendario: $1140 \pm 80$ años DC.

Contexto diagnóstico fechado: Sector de una población agrícola-marítima tardía (cementerio) correspondiente a la fase San Miguel, con tiestos clásicos en la literatura. Se fecha el contexto típico que acompaña a los tiestos San Miguel en el valle inferior de San Miguel de Azapa.

Comentario: Tiempo coherente para determinar el "Período Medio a San Miguel típico" (Espoueys 1971). El término "Período Medio" debe entenderse para la fase San Miguel que el autor tiende a subdividirla de acuerdo a los estudios actuales. 


\section{Muestra 19}

Sitio: Azapa 8.

Ubicación: I región, localidad San Miguel de Azapa, valle de Azapa, cerca del puerto de Arica.

Subárea ecológica: Valle interior en contacto con el Pacífico (subárea de Valles Transversales Norte).

Tipo de sitio: Cementerio.

Tipo de muestra: Textil (estera).

Localización en el sitio: Tumba M-27.

Nombre del laboratorio: UCLA Radiocarbon.

Colector de la muestra: J. Montané (1965), Museo Nacional de Historia Natural, Santiago.

Sigla y número del laboratorio: UCLA 1294 C.

Resultado recibido: Edad absoluta: $580 \pm 80$ años AP.

Edad calendario: $1370 \pm 80$ años DC.

Contexto diagnóstico fechado: Fecha la fase San Miguel Tardío.

\section{Muestra 20}

Sitio: Azapa 8.

Ubicación: Provincia de Tarapacá, depto. de Arica, localidad San Miguel de Azapa, valle de Azapa, cerca del puerto de Arica ( $18^{\circ} 34^{\prime}$ Lat. S; $70^{\circ}$ 12' Long. O).

Subárea ecológica: Valle inferior con contacto con el Pacífico (subárea Valles Transversales Norte).

Tipo de sitio: Cementerio.

Tipo de muestra: Tejido de fibra vegetal.

Localización en el sitio: Tumba M-45.

Nombre del laboratorio: UCLA Radiocarbon.
Colector de la muestra: O. Espoueys (1965), Centro de Antropología, Arica.

Sigla y número del laboratorio: UCLA 1294 A.

Resultado recibido: Edad absoluta: $680 \pm 80$ años AP.

Edad calendario: $1270 \pm 80$ años DC.

Contexto diagnóstico fechado: Sector de una población agrícola-marítima correspondiente a la fase San Miguel en su etapa tardía.

Comentario: De acuerdo a Espoueys (1971), esta fecha ubica la etapa tardía de la fase San Miguel.

\section{Muestra 21}

Sitio: Azapa 8.

Ubicación: I región, localidad San Miguel de Azapa, valle de Azapa, cerca del puerto de Arica.

Subárea ecológica: Valle inferior en contacto con el Pacífico (subárea Valles Transversales Norte).

Tipo de sitio: Cementerio.

Tipo de muestra: Textil.

Localización en el sitio: Tumba M-10.

Nombre del laboratorio: UCLA Radiocarbon.

Colector de la muestra: J. Montané (1965), Museo Nacional de Historia Natural, Santiago.

Sigla y número del laboratorio: UCLA 1294 B.

Resultado recibido: Edad absoluta: $280 \pm 80$ años AP.

Edad calendario: $1670 \pm 80$ años DC.

Contexto diagnóstico fechado: Debería fechar la fase tardía de San Miguel, pero el tiempo determinado resulta anacrónico, no utilizable.

Comentario: Esta muestra es contemporánea a la fecha $1270 \pm 80$ años DC (ver ficha $\mathrm{N}^{\circ} 20$ ) según Espoueys (1971). 


\section{Muestra 22}

Sitio: Pica 8.

Ubicación: I región, localidad Matilla, sector banda sur, valle de Quisma ( $20^{\circ} 31^{\prime}$ Lat. S; $69^{\circ} 23^{\prime}$ Long. O).

Subárea ecológica: Oasis y valles piemontanos (subárea Valles Transversales Norte), oriente de Pampa del Tamarugal.

Tipo de sitio: Cementerio.

Tipo de muestra: Tejido humano y alimento digerido de un cuerpo adulto.

Localización en el sitio: Cuerpo adulto de la tumba 7, Sección G, a $76 \mathrm{~cm}$ de profundidad de la superficie actual.

Nombre del laboratorio: Instituto Venezolano de Investigaciones Científicas.

Colector de la muestra: L. Núñez, Universidad de Chile, Antofagasta-Iquique.

Sigla y número del laboratorio: IVIC-792.

Resultado calculado: 500-1000 años DC.

Resultado recibido: Edad absoluta: $950 \pm 70$ años AP.

Edad calendario: $1000 \pm 70$ años DC.

Observación del laboratorio: Ver ficha de Caleta Huelén 7, muestra 25.

Contexto diagnóstico fechado: Tumba con cerámica Charcollo (pucos con baños rojos, con motivos rojos irregulares en superficie mal tratada), túnica con decoración Tiwanaku, y cráneos deformados.

Fecha un contexto Tiwanaku colonizador en la población local de los oasis Pica-Matilla.

Comentario: La fecha parece ser correcta. Determina el tiempo en que un sector bien definido del cementerio Pica 8 recibe una oleada o colonia del altiplano inmediato con hombres que portan textiles con diseños similares a la litoescultura y cerámica Tiwanaku en su fase clásica y réplicas supervivientes. Se asocia a tiestos Charcollo, cráneos con la típica deformación procedente del altiplano y otras artesanías populares del Complejo Pica. Puede apreciarse que este grupo fechado a los 1000 años DC, siendo inobjetablemente parte de una penetración Tiwanaku, se ubica en un tiempo inmediatamente posterior o contemporáneo al Complejo Pica. Se trata de una situación cronológica aparentemente controvertida, por cuanto este complejo está asociado a tiestos San Miguel clásicos. Sin embargo, esta sincronía entre un grupo vinculado a Tiwanaku en un denso cementerio con una mayoría notable de rasgos del Complejo Pica (desarrollo local), que no posee estilística Tiwanaku, nos hace pensar que el grupo fechado formaría parte de una colonia Tiwanaku conviviente con la población local de los oasis Pica-Matilla, en un momento más temprano del Complejo Pica Tardío.

Referencia bibliográfica: L. Núñez (1972b, Ms-b).

\section{Muestra 23}

\section{Sitio: Caleta Huelén 2.}

Ubicación: II región, localidad desembocadura del río Loa, sector banda sur.

Subárea ecológica: Valle del Loa en zona de eficiencia de desembocadura en el Pacífico (fricción de la subárea Valles Transversales Norte con la subárea Marítima Norte).

Tipo de sitio: Cementerio.

Tipo de muestra: Carbón de madera.

Localización en el sitio: Tumba 29.

Nombre del laboratorio: Niedersachsischen Landesamt für Bodenforschung, Hannover.

Colector de la muestra: J.C. Spahny, Museo de Ginebra.

Sigla y número del laboratorio: HV-556.

Resultado recibido: Edad absoluta: $1425 \pm 80$ años AP.

Edad calendario: 525 \pm 80 años DC. 
Contexto diagnóstico fechado: Rasgos funerarios y artefactos tardíos comparables a los contextos agromarítimos procedentes de la costa de Arica, entre las fases San Miguel y Gentilar.

Comentario: Este sitio se reconoce en la obra de J. C. Spahny (1963) como "cementerio No 5" y equivale al yacimiento denominado Caleta Huelén 2 (Núñez 1971).

La fecha parece ser algo temprana en relación a las dataciones para la fase San Miguel.

Referencias bibliográficas: Spahny (1963), L. Núñez (1971).

\section{Muestra 24}

Sitio: Caleta Huelén 10.

Ubicación: II región, localidad desembocadura del Loa, banda sur.

Subárea ecológica: Zona de eficiencia de desembocadura de río en el Pacífico (fricción entre la subárea Valles Transversales Norte y subárea Marítima Norte).

Tipo de sitio: Cementerio (túmulos).

Tipo de muestra: Osamentas humanas carbonizadas.

Localización en el sitio: Tumba 39.

Nombre del laboratorio: Niedersachsischen Landesamt für Bodenforschung, Hannover.

Colector de la muestra: J. C. Spahny, Museo de Ginebra.

Sigla y número del laboratorio: HV-557.

Resultado recibido: Edad absoluta: $1735 \pm 100$ años AP.

Edad calendario: 215 \pm 100 años DC.

Contexto diagnóstico fechado: Artefactos de explotación marítima con ingredientes cerámicos tempranos (formas de cucurbitas) y placas de cobre. Evidencias agropecuarias tempranas relacionadas con un campo de enterramientos en túmulos correspondientes al poblamiento cerámico temprano de la costa, procedente de tierras altas.

Comentario: Este sitio se reconoce como "cementerio No 3" en la publicación de Spahny (1963). Equivale al yacimiento de tumbas-túmulos denominado Caleta Huelén 10 (L. Núñez 1971)

Referencias bibliográficas: Spahny (1963), L. Núñez (1971).

\section{Muestra 25}

\section{Sitio: Caleta Huelén 7.}

Ubicación: II región, localidad desembocadura del río Loa, banda sur.

Subárea ecológica: Valle del Loa en zona de eficiencia de desembocadura en el Pacífico (fricción de subárea Valles Transversales Norte y subárea Marítima Norte).

Tipo de sitio: Cementerio.

Tipo de muestra: Fragmento de cestería coiled y fibras vegetales torcidas.

Localización en el sitio: Tumba 1, a $65 \mathrm{~cm}$ de profundidad.

Nombre del laboratorio: Instituto Venezolano de Investigaciones Científicas.

Colector de la muestra: L. Núñez (1968), Universidad de Chile, Antofagasta-Iquique.

Sigla y número del laboratorio: IVIC-788.

Resultado calculado: 100-400 años DC.

Resultado recibido: Edad absoluta: $2030 \pm 80$ años AP.

Edad calendario: $80 \pm 80$ años AC.

Observación del laboratorio: "De acuerdo a los convenios internacionales existentes entre los laboratorios de radiocarbono, los cálculos de las edades fueron hechos usando 5568 años como la vida media del $\mathrm{C}^{14}$. El estándar moderno es $95 \%$ de la actividad de 
NBS Acido Oxálico, el año de referencia es 1950 DC y los errores son la desviación estándar (68\% de probabilidades)" (M. A. Tamers, com. pers., agosto 4 de 1970).

Contexto diagnóstico fechado: El contexto funerario (Tumba 1) fecha a un cuerpo adulto flectado con cubiertas de esteras de fibra vegetal, plumas y atado de fibra vegetal en el interior del paladar. Se incluyen además tiestos cerámicos botelliformes y campaniformes de superficies pulidas, minerales de cobre, artefactos de recolección marítima, cestería coiled, cordelería gruesa, bolsas de fibrasred, algodón, calabaza, cuchillos de cuarzo y lana presumiblemente de llamas.

Comentario: La fecha determina el tiempo del arribo a esta parte de la costa, de un pequeño grupo humano dedicado a la explotación marítima, pero que posee una fuerte tradición ceramista con finas técnicas de pulimentos. Son típicos los tiestos campaniformes de bases planas con superficies rojas, negras y plomas debidamente pulidas. Entre otros indicadores hay tiestos café alisados con bordes finamente punteados. Son portadores de tradiciones procedentes de tierras altas (rasgos agropecuarios). Por ahora hay evidentes relaciones con los rasgos cerámicos pulidos y bordes punteados de la aldea Caserones en la quebrada de Tarapacá. Se acepta en forma preliminar que el grupo parcialmente fechado sea una colonia con evidencia pretardía, dependiente de comunidades agrícolas internas a la costa. El tiempo asignado al comienzo de nuestra era parece correcto, y por la baja densidad de enterramientos en una formación tumular homogénea, la fecha podría servir para la determinación temporal del grupo en su totalidad.

Referencia bibliográfica: L. Núñez (1971).

\section{Muestra 26}

Sitio: Caleta Huelén 10.

Ubicación: II región, localidad de desembocadura del río Loa, banda sur.

Subárea ecológica: Valle del Loa en zona de eficiencia de desembocadura de río al Pacífico. (fricción subárea Valles Transversales Norte y subárea Marítima Norte).
Tipo de sitio: Cementerio.

Tipo de muestra: Fragmento textil de tipo entrelazado (lana de camélido).

Localización en el sitio: Túmulo funerario 1, en el contexto de ofrendas, a $62 \mathrm{~cm}$ desde la superficie actual.

Nombre del laboratorio: Instituto Venezolano de Investigaciones Científicas.

Colector de la muestra: L. Núñez (1968), Universidad de Chile, Antofagasta-Iquique.

Sigla y número del laboratorio: IVIC 789.

Resultado calculado: 200-500 años DC.

Resultado recibido: Edad absoluta: $2000 \pm 70$ años AP.

Edad calendario: $50 \pm 70$ años AC.

Observación del laboratorio: Ver ficha de Caleta Huelén 7, muestra 25.

Contexto diagnóstico fechado: El contexto funerario fecha un párvulo cubierto de tejido grueso elaborado en lana presumiblemente de llama (Tumba 1), ubicado bajo una cubierta entrelazada de ramas. La asociación diagnóstica presenta tiestos botelliformes de superficie estriada y un puco con forma de zapallo, con superficie pulida. Se registraron además, bolsas de fibra vegetal-red, cestería coiled, bolsas de lana y anzuelos de quisco.

Comentario: La fecha parece muy coherente para una población densa que abarcó un campo de túmulos considerable. Seguramente que este tiempo pertenece a una etapa del pleno uso del área de enterramientos, y su valor temporal no puede ser utilizado para el yacimiento en su totalidad. La economía está orientada a una intensa explotación marítima, con controles artesanales muy avanzados (tratamiento en superficies pulidas, placas de cobre, etc.). Los rasgos agropecuarios proceden de focos agrícolas al interior de la costa.

Referencia bibliográfica: L. Núñez (1971). 


\section{Muestra 27}

Sitio: Caleta Huelén 10A.

Ubicación: II región, localidad de desembocadura del río Loa, banda sur.

Subárea ecológica: Zona de eficiencia de desembocadura de río en el Pacífico (fricción entre la subárea Valles Transversales Norte y subárea Marítima Norte).

Tipo de sitio: Cementerio.

Tipo de muestra: Madera, al parecer totalmente carbonizada.

Localización en el sitio: Tumba 7 (Sector A, sin túmulos) a $43 \mathrm{~cm}$ de profundidad de la actual superficie.

Nombre del laboratorio: Instituto Venezolano de Investigaciones Científicas.

Colector de la muestra: L. Núñez (1968), Universidad de Chile, Antofagasta-Iquique.

Sigla y número del laboratorio: IVIC-790.

Resultado calculado: 500-1000 años DC.

Resultado recibido: Edad absoluta: $2320 \pm 80$ años AP.

Edad calendario: $370 \pm 80$ años AC.

Observación del laboratorio: Ver ficha de Caleta Huelén 7, muestra 25.

Contexto diagnóstico fechado: El contexto funerario fechado presenta un cuerpo adulto flectado arreglado en un fardo de lana (¿llama?) cubierto de una estera de fibra vegetal. La asociación incluye: tubo de insuflar narcóticos, madero carbonizado, cabecera de arpón de hueso, cestería coiled, bolsas de tejido de lana, paño de lana, piedra horadada y restos de mariscos.

Comentario: Si la fecha temprana es correcta, dataría un sector bien diferenciado del yacimiento de túmulos (CaH-10). Se trata de un sector sin túmulos, en donde los enterramientos se prepararon en fosos amorfos, por las buenas condiciones del subsuelo.
Podría considerarse como el comienzo de la ocupación en una etapa anterior al desarrollo del resto del campo de túmulos. Es probable que en esta etapa temprana la elaboración de cerámica era escasa. Las tumbas estudiadas no poseen cerámica, por razones más accidentales que culturales; el contexto funerario del sector asegura que este grupo humano debió elaborar cerámica. En la superficie de las tumbas excavadas y entre sus rellenos aparecieron fragmentos que eventualmente podrían considerarse como ofrendas sincrónicas a los enterramientos, pero alteradas por la cercanía a la superficie. La mayoría de los artefactos recuperados están vinculados con la explotación marítima.

Referencia bibliográfica: L. Núñez (1971).

\section{Muestra 28}

\section{Sitio: Caleta Huelén 43.}

Ubicación: II región, localidad de desembocadura del río Loa, banda sur.

Subárea ecológica: Valle del Loa en zona de eficiencia de desembocadura del río al Pacífico (fricción de subárea Valles Transversales Norte y subárea Marítima Norte).

Tipo de sitio: Cementerio.

Tipo de muestra: Tejido humano (segmento de cuerpo adulto momificado por factores climáticos).

Localización en el sitio: Tumba 10, a $63 \mathrm{~cm}$ de profundidad de la superficie actual.

Nombre del laboratorio: Instituto Venezolano de Investigaciones Científicas.

Colector de la muestra: L. Núñez (1970), Universidad de Chile, Antofagasta-Iquique.

Sigla y número del laboratorio: IVIC-791.

Resultado calculado: 0-300 años DC.

Resultado recibido: Edad absoluta: $1130 \pm 80$ años AP.

Edad calendario: $820 \pm 80$ años DC.

Observación del laboratorio: Ver ficha de Caleta Huelén 7, muestra 25. 
Contexto diagnóstico fechado: El contexto funerario fechado asociado a un cuerpo adulto flectado presenta cerámica de superficie café alisada, capacho de carga, palos de extremos agudos, tejidos entrelazados y gruesos, bolsa con maíz y sandalias de cuero.

Comentario: La fecha, aunque parece ser algo tardía, puede utilizarse con el sigma menos. La explicación podría basarse en que la muestra proviene de un borde del yacimiento, cuando el campo de túmulos había logrado su máximo desarrollo. El total de 210 túmulos viene a confirmar que la ocupación debió ser densa a través de una cronología más temprana. La fecha recibida dataría prácticamente el fin de la población, cuando el maíz estaba bien consolidado, dentro de un contexto de explotación marítima mayoritaria. Los estudios en el sitio hacen prever que se trata de una población dedicada a la explotación del mar, con uso de cerámica de superficie café estriada, con formas y técnicas no bien controladas y de escasa frecuencia. Los artefactos más indicadores como textiles, líticos, cerámica, y el tipo de enterramiento (un cuerpo por túmulo con cubierta vegetal de esteras y ramas) son algunos rasgos seguramente pretardíos, que eventualmente se ubicarían en la fase final de las poblaciones con túmulos en el área. Hay otra fecha más temprana obtenida del centro del sitio (ver ficha siguiente).

\section{Referencia bibliográfica: L. Núñez (1971).}

\section{Muestra 29}

\section{Sitio: Caleta Huelén 43.}

Ubicación: II región, localidad de desembocadura del río Loa, banda norte $\left(21^{\circ} 25^{\prime}\right.$ Lat. $\mathrm{S} ; 70^{\circ}$ 25 ' Long. O).

Subárea ecológica: Valle del Loa en zona de eficiencia de desembocadura en el Pacífico (fricción entre la subárea Valles Transversales Norte y subárea Marítima Norte).

Tipo de sitio: Cementerio.

Tipo de muestra: Textil (90 gr) elaborado en lana de camélido.

Localización en el sitio: Túmulo funerario $\mathrm{N}^{\circ} 13$.

Nombre del laboratorio: Laboratorio de Radiocarbón de la Universidad Gakushuin, Tokio.
Colectores de la muestra: Núñez y colaboradores (1971), Universidad de Chile, AntofagastaIquique.

Sigla y número del laboratorio: GAK-3544.

Resultado calculado: 500-800 años DC.

Resultado recibido: Edad absoluta: $2400 \pm 90$ años AP.

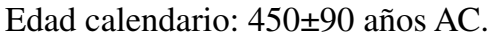

Observación del laboratorio: "La edad de GAK-3544 es más temprana de lo que usted esperaba, pero parece ser segura" (K. Kigoshi, com. pers. 1971). "El cálculo de edad se basa en el promedio de vida Libby: 5570 años, y los indicadores de errores $( \pm)$ son los años correspondientes a las desviaciones estándar de rayos beta contados los errores estadísticamente" (K. Kigoshi, com. pers. 1971).

Contexto diagnóstico fechado: El contexto funerario fecha un cuerpo adulto desarticulado. Del sector no alterado se recuperó una brocha típica para contextos tempranos, un artefacto de hueso como punzón con canal (¿desangrador?), evidencia de sandalia de cuero, tejido anudado de lana gruesa tipo red, cestería coiled, y una hoja lítica de base redondeada.

Comentario: El objetivo de esta segunda fecha para el yacimiento $\mathrm{CaH}-43$ consistió en contraponer otra medida proveniente esta vez del centro del yacimiento. La muestra 28, al utilizarla como un eventual fin del desarrollo de la ocupación, dejó planteado el problema de ubicar una mayor profundidad temporal, sobre todo si aceptamos que un campo de 210 túmulos implica un lapso de tiempo significativo. La fecha recibida podría servir para colocar aquí el comienzo de la ocupación y/o enterramientos. La fecha calculada resultó muy tardía en relación al resultado del laboratorio. Pero nuestro cálculo se basaba en parte en la ficha 28 , aunque intuimos que debería ser sensiblemente más temprano en relación a la magnitud del yacimiento.

Este sector central fechado más tempranamente ofrece contextos que no se contradicen en lo cultural con las evidencias marginales eventualmente más tardías. En general, el yacimiento se presenta con cierta homogeneidad cultural dada por la persistencia de rasgos comunes en la funebria: cubiertas de piel 
de pelícanos, cestería coiled, tejidos de fibra vegetal, punto de red, cabeceras de arpones de madera, esteras de fibra vegetal, vainas de algarrobo, cuentas de concha, sombreros de tejidos de punto con adornos escalerados polícromos, cabelleras con dos atados laterales, maíz, pesas líticas con acanaladuras, posible guano de llamas, brocha y fragmento de propulsor. Finalmente, la cerámica monocroma alisada de baja frecuencia se distribuye sin grandes variaciones en la totalidad del sitio. Esta aparente homogeneidad deberá estudiarse más detenidamente si fuera cierto que entre el eventual comienzo y fin de la ocupación del yacimiento se cubrió un lapso de cerca de 1270 años. Esta fecha temprana puede utilizarse con seguridad en relación al tiempo bastante similar obtenido en Conanoxa, también en contextos funerarios de túmulos.

Referencia bibliográfica: L. Núñez (1971).

\section{Muestra 30}

\section{Sitio: Caleta Huelén 42.}

Ubicación: II región, localidad de desembocadura del río Loa, banda norte $\left(21^{\circ} 25^{\prime}\right.$ Lat. $\mathrm{S} ; 70^{\circ}$ 25 ' Long. O).

Subárea ecológica: Valle del Loa en zona de eficiencia de desembocadura al Pacífico (fricción entre la subárea Valles Transversales Norte y subárea Marítima Norte).

Tipo de sitio: Aldea (con estructuras circulares semisubterráneas y sectores de basurales asociados).

Tipo de muestra: Carbón de restos óseos (180 gr).

Localización en el sitio: Unidad 1, Corte 1 (bolsón en el piso más temprano del depósito estratificado, del comienzo de la ocupación).

Nombre del laboratorio: Laboratorio de Radiocarbón de la Universidad de Gakushuin, Tokio.

Colectores de la muestra: Núñez y colaboradores (1971), Universidad de Chile, AntofagastaIquique.

Sigla y número del laboratorio: GAK-3546.
Resultado calculado: 2000-2500 años AC.

Resultado recibido: Edad absoluta: $4780 \pm 100$ años AP.

Edad calendario: 2830 \pm 100 años AC.

Observación del laboratorio: "Los huesos quemados fueron tratados con el procedimiento de ácido nítrico y fue datado sobre los materiales orgánicos quemados" ( K. Kigoshi com. pers., 1971).

Contexto diagnóstico fechado: La muestra fecha correctamente el comienzo de la estratificación de basuras en el sector monticular de mayor potencia del yacimiento. Determina el tiempo del depósito inicial de desperdicios preferentemente marítimos (pescados). Los artefactos recuperados forman parte de un conjunto preagrícola típico para los asociados culturales del nivel del anzuelo de cactus (tradición Chinchorro).

Comentario: El sitio CaH-42 se caracteriza por constituir un conglomerado de recintos habitacionales de plantas circulares, algunos de los cuales aflora en la superficie de depósito de basuras que cubre el sitio. La fecha determinaría el momento en que se impone sobre la terraza estéril el patrón de poblamiento a base de recintos semicirculares y semisubterráneos. Habría una relación sincrónica entre las primeras construcciones habitacionales y las primeras basuras datadas.

Referencia bibliográfica: Núñez y colaboradores (Ms, Ms-a).

\section{Muestra 31}

\section{Sitio: Caleta Huelén 42.}

Ubicación: II región, localidad de desembocadura del río Loa, banda norte $\left(21^{\circ} 25^{\prime}\right.$ Lat. $\mathrm{S} ; 70^{\circ}$ 25 ' Long. O).

Subárea ecológica: Valle del Loa en zona de eficiencia de desembocadura del río al Pacífico (fricción entre la subárea Valles Transversales Norte y subárea Marítima Norte).

Tipo de sitio: Aldea. 
Tipo de muestra: Madera (18 gr), fragmento de cabecera de arpón.

Localización en el sitio: Muestra asociada al esqueleto $\mathrm{N}^{\mathrm{o}} 12$, dispuesto bajo el piso-sello cuarto o más temprano, en el interior de la estructura habitacional $\mathrm{N}^{\mathrm{o}} 1$.

Nombre del laboratorio: Laboratorio de Radiocarbón de la Universidad de Gakushuin, Tokio.

Colectores de la muestra: Núñez y colaboradores (1971), Universidad de Chile, AntofagastaIquique.

Sigla y número del laboratorio: GAK-3545.

Resultado calculado: 2000-2500 años AC.

Resultado recibido: Edad absoluta: $3780 \pm 90$ años AP.

Edad calendario: $1830 \pm 90$ años AC.

Contexto diagnóstico fechado: La fecha determina el momento en que se deposita en la base de una habitación el cuerpo extendido de un adulto, cuando el recinto se encontraba en uso. El enterramiento debe pertenecer a la población original eventualmente contemporánea al máximo desarrollo de la aldea, es decir, cuando el yacimiento se encontraba con la mayor capacidad de instalación.

Junto al esqueleto $\mathrm{N}^{\circ} 12$ se ubicaron rasgos típicos para esta población, entre los que destacamos las cabeceras de arpones y hojas taltaloides.

Comentario: Esta determinación radiocarbónica fecha el contexto funerario de los enterramientos más tempranos en las bases de los recintos habitacionales. Presenta, a pesar de esto, una significativa diferencia de 1000 años entre el comienzo de la depositación de basuras y los enterramientos referidos. No hay discrepancias sólidas entre los indicadores recuperados de los enterramientos más tempranos y los de los primeros estratos de desperdicios. Nos parece demasiada la distancia temporal, sobre todo si aceptamos que los enterramientos extendidos poseen rasgos chinchorroides (pasta en concavidades orbitales, etc.). Una interpretación posible podría ser que los hombres comienzan a usar las bases de los recintos como lugares de enterramiento una vez que ya habían transcurrido 1000 años de ocupación del yacimiento. La evidencia estratigráfica habla a favor de una contemporaneidad entre las primeras basuras y las primeras habitaciones típicas del patrón aldeano precerámico.

Referencia bibliográfica: Núñez y colaboradores (Ms, Ms-a).

\section{Muestra 32}

Sitio: Tarapacá 40A.

Ubicación: I región, localidad de Caserones, sector banda norte de la quebrada de Tarapacá, tramo inferior.

Subárea ecológica: Zona de fricción entre la quebrada de Tarapacá y Pampa del Tamarugal (subárea Valles Transversales Norte).

Tipo de sitio: Cementerio.

Tipo de muestra: Vaina de algarrobo (Prosopis).

Localización en el sitio: Tumba 62, Sección M', a 57 $\mathrm{cm}$ de profundidad desde la superficie actual.

Nombre del laboratorio: Laboratorio de Radiocarbón de la Universidad de Gakushuin, Tokio.

Colector de la muestra: L. Núñez (1967), Universidad de Chile, Antofagasta-Iquique.

Sigla y número del Laboratorio: GAK-2206.

Resultado calculado: 0-400 años DC.

Resultado recibido: Edad absoluta: $1660 \pm 90$ años AP.

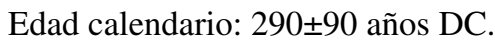

Contexto diagnóstico fechado: La fecha determina el tiempo de un cuerpo y contexto (etapa A) típico del yacimiento (L. Núñez 1970).

Comentario: Esta determinación fecha correctamente una etapa del cementerio Tr-40 que pudo representar a la población inicial de la aldea Caserones. Se trata de una zona de enterramientos separados en 
dos posibles etapas. La etapa A se vincula con una economía arcaica de caza-recolección y horticultura temprana. Sus indicadores señalan la presencia de una densa población con turbantes deformadores, tumbas con postes gruesos, proliferación de cestería, tejidos burdos y gruesos, práctica ausencia de cerámica (tres casos en 100 enterramientos), énfasis en recolección de quinoa, algarrobo y horticultura de zapallos, calabazas y posiblemente maíz. El predominio de artefactos y evidencias derivadas del trabajo de caza y recolección en el perfil altiplanocosta, nos hacen prever que esta población temprana pone un énfasis especial en la recolección local, junto a la práctica de los primeros cultivos económicos. Dentro de este contexto sin agricultura avanzada, la fecha es coherente y se apoya en una segunda del mismo yacimiento (ver muestra 33 )

Referencia bibliográfica: L. Núñez (1970).

\section{Muestra 33}

Sitio: Tarapacá 40A.

Ubicación: I región, localidad de Caserones, sector banda norte de la quebrada de Tarapacá, tramo inferior.

Subárea ecológica: Zona de fricción entre la quebrada de Tarapacá y Pampa del Tamarugal (subárea Valles Transversales Norte).

Tipo de sitio: Cementerio.

Tipo de muestra: Cabello humano.

Localización en el sitio: Cuerpo del enterramiento $\mathrm{N}^{\mathrm{o}} 29$, Sección M', a $63 \mathrm{~cm}$ de profundidad de la superficie actual.

Nombre del laboratorio: Laboratorio de Radiocarbón de la Universidad de Gakushuin, Tokio.

Colector de la muestra: L. Núñez (1967), Universidad de Chile, Antofagasta-Iquique.

Sigla y número del laboratorio: GAK-2893.

Resultado calculado: 0-400 años DC.

Resultado recibido: Edad absoluta: $1590 \pm 170$ años AP.
Edad calendario: $360 \pm 170$ años DC.

Contexto diagnóstico fechado: La fecha determina el tiempo de un cuerpo típico del yacimiento (etapa A).

Comentario: La población de enturbantados de Tarapacá 40A tendría un hito temporal inferior del orden de los 290 años DC. Esta nueva fecha de 360 años DC vendría a otorgar un hito superior coherente y acorde a lo esperado.

Debe recordarse que la fecha recibida proviene de Tr-40A, es decir, de la etapa de desarrollo cazadorrecolector-horticultor. La distancia de espacio entre la tumba 29 y la anterior 62 , nos podría señalar que la diferencia de 70 años entre ambas pueda interpretarse como acorde al tiempo de desarrollo del cementerio. Esta determinación precisa mejor el tiempo de una densa población de enturbantados con tendencia a ocupar asentamientos semiestables relacionados con la nueva economía dada por la horticultura y/o agricultura incipiente. Representa una base predominante de caza-recolección, dentro de un circuito trashumántico, que mantenía a la parte baja de la quebrada de Tarapacá como un foco de asentamiento estable cuando las condiciones ecológicas eran favorables (cosechas de algarrobo y horticultura de estación).

Debe acotarse que la parte $\mathrm{B}$ del mismo cementerio implica el desarrollo de la agricultura mayoritaria, procedente de tierras altas y contemporánea a Tiwanaku, con una proliferación de cerámica extraordinaria (tiestos negro y rojo pulidos, de superficies café alisados, bordes punteados, etc.) que ocurren también en la aldea de Caserones; es obvio suponer que esta segunda oleada de la misma población (B) al ser portadora del cambio agrícola como base predominante de producción pasa a consolidar la orientación agrícola de la aldea de Caserones.

Referencia bibliográfica: L. Núñez (1970).

\section{Muestra 34}

Sitio: Tarapacá 18.

Ubicación: I región, localidad de Huarasiña, sector banda sur del tramo inferior de la quebrada de Tarapacá. 
Subárea ecológica: Quebrada en fricción con Pampa del Tamarugal (subárea Valles Transversales Norte).

Tipo de sitio: Campamento.

Tipo de muestra: Carbón vegetal.

Localización en el sitio: Ordenamiento habitacional (?) A (a $15 \mathrm{~cm}$ bajo la actual superficie).

Nombre del laboratorio: Laboratorio de Radiocarbón de la Universidad de Gakushuin, Tokio.

Colector de la muestra: D. True (1967), Universidad de California.

Sigla y número del laboratorio: GAK-2433.

Resultado recibido: Edad absoluta: $3910 \pm 170$ años AP.

Edad calendario: $1960 \pm 170$ años AC.

Contexto diagnóstico fechado: Numerosos artefactos pesados elaborados a partir de núcleos (martillos, percutores, cepillos, raspadores, choppers). Es significativa la ausencia de artefactos de lascas finas con trabajos bifaciales.

Comentario: Campamento con depósitos de restos orgánicos (huesos de mamíferos) y basuras asociadas a artefactos líticos. Los bolsones con basuras son, en general, de poca potencia. Parece segura la presencia de camélidos.

Referencias bibliográficas: True y colaboradores (1970), True y Matson (1970).

\section{Muestra 35}

Sitio: Tarapacá 12.

Ubicación: I región, localidad de Huarasiña, sector banda sur de la quebrada de Tarapacá, tramo inferior.

Subárea ecológica: Quebrada en fricción con Pampa del Tamarugal (subárea Valles Transversales Norte).

Tipo de sitio: Campamento.
Tipo de muestra: Carbón vegetal.

Localización en el sitio: Muestra obtenida de la trinchera A, cuadrícula 2, nivel $2(10-20 \mathrm{~cm})$ de un fogón.

Nombre del laboratorio: Laboratorio de Radiocarbón de la Universidad de California, Los Angeles.

Colector de la muestra: D. True (1967), Universidad de California.

Sigla y número del laboratorio: UCLA 1293.

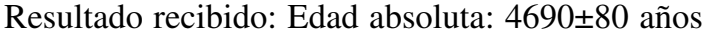
AP.

Edad calendario: $2740 \pm 80$ años AC.

Contexto diagnóstico fechado: Cuchillos de lascas con trabajo bifacial, cuchillos o puntas de formas triangulares con bases cóncavas, herramientas pesadas (percutores o martillos, choppers, cepillos, raspadores), manos de molienda.

Comentario: Este campamento posee sectores estériles y concentraciones de basuras bien identificadas en las excavaciones a través de sus bolsones o concentraciones en pequeñas concavidades. Aparecen evidencias de fogones y artefactos entre la cubierta de desperdicios.

Referencias bibliográficas: True y colaboradores (1970), True y Matson (1970).

\section{Muestra 36}

Sitio: Tarapacá 2A.

Ubicación: I región, localidad de Huarasiña, sector banda sur de la quebrada de Tarapacá en su tramo inferior.

Subárea ecológica: Quebrada en fricción con Pampa del Tamarugal (subárea Valles Transversales Norte).

Tipo de sitio: Campamento.

Tipo de muestra: Carbón vegetal. 
Localización en el sitio: Muestra obtenida de un fogón a $20 \mathrm{~cm}$ de profundidad en la trinchera A-A, cuadrícula 2.

Nombre del laboratorio: Laboratorio de Radiocarbón de la Universidad de Gakushuin, Tokio.

Colector de la muestra: D. True (1967), Universidad de California.

Sigla y número del laboratorio: GAK-2205.

Resultado recibido: Edad absoluta: 5970 \pm 120 años AP.

Edad calendario: 4020 \pm 120 años AC.

Contexto diagnóstico fechado: Puntas de proyectiles de bases pedunculadas con bordes dentados, elaboradas con fino retoque presionado.

Comentario: La muestra parece fechar correctamente un momento significativo de la ocupación del campamento preagrícola $\mathrm{Tr}$-2A. El depósito tiende a ser superficial, con desperdicios dispersos concentrados en pequeñas depresiones. En esta débil capa de desperdicios hay evidencias de fogones y artefactos líticos. No hay una estratificación propiamente tal, aunque el depósito en el sector más potente presenta profundidades menores a los $40 \mathrm{~cm}$.

Referencias bibliográficas: Ver ficha $\mathrm{N}^{\circ} 34$.

\section{Muestra 37}

Sitio: Tarapacá 14A.

Ubicación: I región, localidad de Huarasiña, sector banda sur de la quebrada de Tarapacá, tramo inferior.

Subárea ecológica: Quebrada en fricción con Pampa del Tamarugal (subárea Valles Transversales Norte).

Tipo de sitio: Campamento.

Tipo de muestra: Carbón vegetal.

Localización en el sitio: Nivel inferior del fogón básico estratificado, de la estructura habitacio- nal $\mathrm{N}^{\mathrm{o}} 5$ (estrato de carbón y ceniza ubicado inmediatamente sobre el piso).

Nombre del laboratorio: Laboratorio de Radiocarbón de la Universidad del Estado de Washington.

Colector de la muestra: D. True (1967), Universidad de California.

Sigla y número del laboratorio: WSU-987.

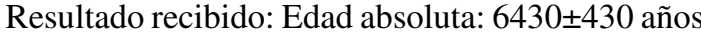
AP.

Edad calendario: $4480 \pm 430$ años AC.

Contexto diagnóstico fechado: Señala el comienzo de la ocupación en casas-pozos precerámicos de la quebrada de Tarapacá. No determina el tiempo de alguna industria lítica definida o asociada.

Comentario: En el sitio Tr-14A hay un sector con casas-pozos dispuestas en leves depresiones cortadas en la base de caliche, que sirvió a su vez como piso compacto de la ocupación. Cada unidad habitacional tendía a presentar un fogón central. En dos unidades excavadas (estructuras habitacionales 3 y 4), existían evidencias estratificadas.

Referencias bibliográficas: Ver ficha $\mathrm{N}^{\circ} 34$. True y Núñez (Ms).

\section{Muestra 38}

Sitio: Tarapacá 14A.

Ubicación: I región, localidad de Huarasiña, sector banda sur de la quebrada de Tarapacá, tramo inferior.

Subárea ecológica: Quebrada en fricción con Pampa del Tamarugal (subárea Valles Transversales Norte).

Tipo de sitio: Campamento.

Tipo de muestra: Carbón vegetal (madera).

Localización en el sitio: Segundo nivel del fogón básico estratificado de la vivienda $\mathrm{N}^{\circ} 5$, en el sector con recintos habitacionales del yacimiento Tr-14A. 
Nombre del laboratorio: Laboratorio de Radiocarbón de la Universidad de Gakushuin, Tokio.

Colector de la muestra: D. True (1967), Universidad de California.

Sigla y número del laboratorio: GAK-2529.

Resultado recibido: Edad absoluta: 4780 \pm 130 años AP.

Edad calendario: $2830 \pm 130$ años AC.

Contexto diagnóstico fechado: Sitúa a un conjunto de puntas lanceoladas bifaciales, cuchillos apuntados y artefactos más burdos (percusión).

Comentario: La fecha señala el tiempo en que se desarrolló el estrato II de una habitación en forma de pozo o de depresión semisubterránea $\left(\mathrm{N}^{\mathrm{o}} 5\right)$ en el campamento precerámico (sector 2).

Referencia bibliográfica: True y Núñez (Ms).

\section{Muestra 39}

Sitio: Tarapacá 14A.

Ubicación: I región, localidad de Huarasiña, sector banda sur de la quebrada de Tarapacá, tramo inferior.

Subárea ecológica: Quebrada en fricción con Pampa del Tamarugal (subárea Valles Transversales Norte).

Tipo de sitio: Campamento.

Tipo de muestra: Carbón vegetal.

Localización en el sitio: Trinchera de prueba $\mathrm{N}^{\mathrm{o}} 2$ (10 $\mathrm{cm}$ de profundidad).

Nombre del laboratorio: Laboratorio de Radiocarbón de la Universidad de Gakushuin, Tokio.

Colector de la muestra: D. True (1967), Universidad de California.

Sigla y número del laboratorio: GAK-2432.

Resultado recibido: Edad absoluta: $6830 \pm 270$ años AP.
Edad calendario: 4880 \pm 270 años AC.

Contexto diagnóstico fechado: Puntas en forma de hojas bien elaboradas de tamaños medianos, caracterizadas por sus bordes aserrados y varios tipos de artefactos pesados, raspadores.

Comentario: La muestra proviene del sector 14A o porción de campamento con una cubierta de arena eólica que conserva concentraciones de desperdicios, fragmentos y artefactos líticos significativos. Se ubicaron fogones y cavidades con restos orgánicos. No hay evidencias de recintos habitacionales.

Referencia bibliográfica: True y Núñez (Ms).

\section{Muestra 40}

Sitio: Cáñamo 1.

Ubicación: I región, localidad de Iquique, sector Patillo-Patache $\left(20^{\circ} 48^{\prime}\right.$ Lat. S; $70^{\circ} 12^{\prime}$ Long. O).

Subárea ecológica: Marítima Norte (ausencia de zona de eficiencia de desembocadura de río, eventual asociación a posible recurso de vertiente).

Tipo de sitio: Basural.

Tipo de muestra: Carbón vegetal (120 gr).

Localización en el sitio: Estrato inferior, en fogón básico del comienzo de la ocupación, a $195 \mathrm{~cm}$ de profundidad.

Nombre del laboratorio: Universidad de Tokio.

Colector de la muestra: L. Núñez (1967), Universidad de Chile, Antofagasta-Iquique.

Sigla y número del laboratorio: TK-102.

Resultado calculado: 3000-3500 años AC.

Resultado recibido: Edad absoluta: $3880 \pm 130$ años AP; 4000 \pm 140 años AP.

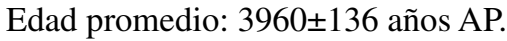

Edad calendario promedio: 2010ะ136 años AC. 
Observación del laboratorio: La muestra TK-102 dio lugar a tres fechas bien coherentes que, a su vez, conformaron un promedio utilizado como fecha representativa.

Contexto diagnóstico fechado: Esta fecha promedio es el resultado de medidas de una muestra. Son muy homogéneas y marcan un hito temporal significativo en la costa sur de Iquique. Se trata del tiempo inicial o de las primeras ocupaciones preagrícolas en la costa Patillo-Patache, sin recursos de desembocadura de ríos. La muestra proviene de la estratificación más profunda del basural con asociaciones a anzuelos de quisco, anzuelos de barbas de ballena, industria lítica de rodados, litos con pintura roja, anzuelos compuestos, evidencias de barbas de cabeceras compuestas, industria lítica de cuchillos y puntas presionadas, cordelería y tejidos de fibra vegetal, cabeceras de arpones de hueso, cestería coiled. Ausencia de evidencias agrícolas y cerámica.

Comentario: La fecha promedio es correcta para un asentamiento orientado exclusivamente a la explotación marítima en su fase inicial. Corresponde a los grupos preagrícolas tardíos establecidos en la costa de interfluvio. Sus contextos a grandes rasgos pueden ajustarse al llamado Segundo Nivel Precerámico (Bird 1946), en su fase tardía. Sería esta determinación la base cronológica más temprana de la secuencia de Cáñamo.

Referencia bibliográfica: Núñez y colaboradores (Ms).

\section{Muestra 41}

\section{Sitio: Cáñamo 1.}

Ubicación: I región, localidad de Cáñamo, sector Patillo-Patache $\left(20^{\circ} 48^{\prime}\right.$ Lat. S; $70^{\circ} 12^{\prime}$ Long. O).

Subárea ecológica: Marítima Norte (ausencia de zonas de eficiencia de desembocaduras, eventual asociación a recurso de vertiente).

Tipo de sitio: Basural.

Tipo de muestra: Carbón (50 gr).

Localización en el sitio: Estrato Amarillo Tardío (fogón lenticular pequeño, acuñado en el Estrato
Amarillo Tardío) a $10 \mathrm{~cm}$ bajo la actual superficie del basural monticular.

Nombre del laboratorio: Universidad de Tokio.

Colector de la muestra: L. Núñez (1967), Universidad de Chile, Antofagasta-Iquique.

Sigla y número del laboratorio: TK-103.

Resultado calculado: 500-1000 años DC.

Resultado recibido: Edad absoluta: $2840 \pm 130$ años AP; $2770 \pm 130$ años AP.

Edad absoluta promedio: $2810 \pm 130$ años AP.

Edad calendario: 860 \pm 130 años AC.

Observaciones del laboratorio: De una muestra se obtuvieron dos fechados muy coherentes, el promedio es consecuentemente correcto.

Contexto diagnóstico fechado: La fecha ubica el tiempo del pleno desarrollo del último estrato potente o "Amarillo Tardío", que cubre gran parte de la última cubierta ocupacional del basural monticular. El tiempo fechado sitúa a cerámica alisada y estriada, textiles a telar, algodón, maíz, calabazas, cobre, porotos y varias evidencias de explotación marítima tardía.

Comentario: El cálculo previo se estimó tardíamente por la presencia de un tipo cerámico algo similar a los registrados en el oasis de Pica, cuyas fechas conocidas son tardías, inmediatamente preincas. Sin embargo, la fecha recibida resultó ser sensiblemente más temprana. La muestra corresponde al pleno desarrollo del estrato amarillo en la zona cuspidal del túmulo-basural, sin posibilidad de manteo causal de alguna perturbación. La muestra es aceptable para fechar algún momento, quizás inicial, de la estratificación amarilla, cuyo contenido implica un cambio económico básico en relación al resto del depósito francamente no cerámico y no agrícola. La fecha podría utilizarse como una hipótesis de trabajo, en el sentido de que la gente responsable de las primeras basuras del estrato amarillo habría arribado a Cáñamo hacia los 860 años AC o algo más tardíamente, desde pisos ecológicos vinculados con agricultura. Este arribo puede entenderse como un contacto, desde un sector en donde la agricultura del complejo tropical y semitropical estaba en uso 
productivo (valles y oasis adyacentes). Si es así, la fecha es temprana y no tiene réplicas similares a tierras internas a la costa. Por esto se hace necesario una nueva determinación en la parte final del estrato amarillo. La fecha no debe descartarse. De ser así, habría que buscar fechas más tempranas (en basuras) a través de yacimientos internos a la costa desértica de interfluvio.

Referencia bibliográfica: Núñez y colaboradores (Ms).

\section{Muestra 42}

Sitio: RAnL-273 A1.

Ubicación: II región, río Loa, localidad de Chiu Chiu.

Subárea ecológica: Valles Transversales Norte.

Tipo de sitio: Habitación con forma de depresión.

Tipo de muestra: Madera (20 gr).

Localización en el sitio: Relleno no estratificado de un fogón a $150 \mathrm{~cm}$ de profundidad.

Colector de la muestra: G. Pollard (1970).

Sigla y número del laboratorio: I-5.400.

Resultado recibido: Edad absoluta: 2150 \pm 95 años AP.

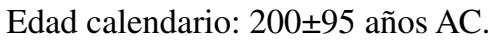

Observación del laboratorio: Tratamientos para eliminar ácidos húmicos y carbonatos.

Contexto diagnóstico fechado: La muestra fecha la fase final del Complejo Vega Alta (Chiu Chiu).

Comentario: Este complejo se compone de pequeños asentamientos semipermanentes, consolidados por crianza de llamas, que en la fase final aportan un carácter más permanente a los asentamientos.

Referencia bibliográfica: Pollard (1971).

\section{Muestra 43}

Sitio: RAnL-216.

Ubicación: II región, zona de confluencia río Loarío Salado.

Subárea ecológica: Valles Transversales Norte.

Tipo de sitio: Campamento abierto.

Tipo de muestra: Carbón.

Localización en el sitio: Nivel superficial $(10 \mathrm{~cm})$ de un área nuclear del campamento abierto Vega Alta.

Colector de la muestra: G. Pollard (1969).

Sigla y número del laboratorio: GX-1.643.

Resultado recibido: Edad absoluta: $1935 \pm 110$ años AP.

Edad calendario: 15 \pm 110 años DC.

Observación del laboratorio: Preparación de la muestra con $\mathrm{H}-\mathrm{C} 1$. No se logró aplicar $\mathrm{NaOH}$. La muestra es demasiado reducida.

Contexto diagnóstico fechado: Comienzo Vega Alta. Campamento abierto con cerámica superficial. Hay registros de puntas pedunculadas y de bases cóncavas o escotadas. Típicos microperforadores, cuchillas, raspadores, percutores, manos de moler (primeras evidencias en la secuencia) y conchas de mar.

Comentario: "La fecha es mucho más joven de lo esperado y la muestra podría tener contaminaciones" (Pollard 1971: 55).

La primera fase demostraría el desplazamiento estacional de pequeños grupos entre la Puna y el río Salado. Existiría en esta fase una tradición de caza-recolección derivada de la secuencia local "precerámica".

La segunda fase adquiere un carácter agropecuario por la incorporación expansiva de la llama.

Referencia bibliográfica: Pollard (1971). 


\section{Muestra 44}

Sitio: RAnL-100.

Ubicación: II región, río Loa, localidad de Chiu Chiu.

Subárea ecológica: Valles Transversales Norte.

Tipo de sitio: Estructuras habitacionales de la aldea Loa I (Chiu Chiu).

Tipo de muestra: Lana y piel de llama (34 gr).

Localización en el sitio: Corte 1, nivel $5(50 \mathrm{~cm}$ bajo la superficie).

Colecta de la muestra: G. Pollard (1969).

Sigla y número del laboratorio: GX-1644.

Resultado recibido: Edad absoluta: $1845 \pm 105$ años AP.

Edad calendario: 105 \pm 105 años DC.

Observación del laboratorio: La muestra se limpió con los tratamientos de diluyentes al calor (H-C 1) y método ultrasónico.

Contexto diagnóstico fechado: La muestra estaba asociada a evidencias de maíz primitivo cultivado. Se trataría de una fecha aceptable para el Complejo Loa en su fase tardía, compuesta por pequeñas aldeas sedentarias.

Comentario: "La fecha es aceptada como representante del comienzo del maíz y de la agricultura de regadío a lo largo del río Loa Medio" (Pollard 1971). Es "equivalente a San Pedro II" (E. Lanning com. pers. a G. Le Paige).

La fase temprana demuestra una economía del tipo Vega Alta.

Referencia bibliográfica: Pollard (1971).

\section{Muestra 45}

Sitio: RAnL-337-1.

Ubicación: II región, sector 9 km aguas abajo de la confluencia Loa-Salado.
Subárea ecológica: Valles Transversales Norte.

Tipo de sitio: Estructura habitacional.

Tipo de muestra: Madera (20 gr).

Localización en el sitio: Depósito de basura en una habitación aislada del Complejo Lasana.

Colector de la muestra: G. Pollard (1970).

Sigla y número del laboratorio: I-5.399.

Resultado recibido: Edad absoluta: $700 \pm 90$ años AP.

Edad calendario: 1250 \pm 90 años DC.

Observación del laboratorio: Tratamiento con $\mathrm{NaOH}$ y H-C 1.

Contexto diagnóstico fechado: Corresponde al Complejo Lasana.

Comentario: Complejo de aldeas aglutinadas y estructuras aisladas, que componen un estadio de desarrollo aldeano avanzado con fortificaciones (Pucara de Lasana). Expansión de la economía agropecuaria.

Referencia bibliográfica: Pollard (1971).

\section{Muestra 46}

Sitio: Cáñamo 3.

Ubicación: I región, sector costa sur de Iquique $\left(20^{\circ}\right.$ 48' Lat. S; 70 12' Long. O).

Subárea ecológica: Marítima (sin desembocadura de ríos).

Tipo de sitio: Cementerio.

Tipo de muestra: Fibra vegetal (fragmento de cestería).

Localización en el sitio: Tumba 15 (cuadrícula A-5) a $45 \mathrm{~cm}$ de la superficie.

Nombre del laboratorio: Universidad de Tokio. 
Colector de la muestra: L. Núñez (1965), Universidad de Chile, Antofagasta-Iquique.

Sigla y número del laboratorio: TK-101.

Resultado calculado: 500-1000 años DC.

Resultado recibido: Edad absoluta: $1190 \pm 60$ años AP.

Edad calendario: 760 \pm 60 años DC.

Contexto diagnóstico fechado: Determina el tiempo de un complejo cultural con evidencia textil Tiwanaku, cerámica roja semipulida y café alisada, de formas cilíndricas con bases planas. Hay además evidencias de cestería, anzuelo de cactus, industria lítica, equipo de insuflar narcóticos y un modelo de balsa de tres cuerpos diseñada para alta navegación por su proa levantada. La población fechada corresponde a un total de 23 tumbas con cuerpos flectados envueltos en esteras de fibras vegetales y pieles de pelícanos. Este complejo podría estar vinculado (cerámica) con los grupos de agricultura temprana del sector de Caserones (quebrada de Tarapacá).

Referencia bibliográfica: Núñez y colaboradores (Ms).

\section{Muestra 47-48}

Sitio: Conanoxa W (a).

Ubicación: I región, valle de Camarones, terraza del sector Conanoxa (19 $02^{\prime}$ Lat. S; 69 $59^{\prime}$ Long. O).

Subárea ecológica: Valle inferior (subárea Valles Transversales Norte) con desagüe al Pacífico.

Tipo de sitio: Campamento.

Localización en el sitio: Depósito estratificado.

Nombre del laboratorio: Instituto Venezolano de Investigaciones Científicas.

Colectores de la muestra: V. Schiappacasse y H. Niemeyer, Museo Nacional de Historia Natural, Academia Chilena de Ciencias Naturales.

Sigla y número del laboratorio: IVIC-875, IVIC876.
Resultado recibido: IVIC-875.

Edad absoluta: 4020 \pm 110 años AP.

Edad calendario: 2070 \pm 110 años AC.

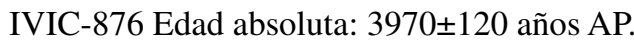

Edad calendario: 2020 \pm 120 años AC.

Contexto diagnóstico fechado: Rasgos culturales de la llamada Cultura Conanoxa del Precerámico Tardío.

Comentario: Ambas fechas comprueban la primera determinación de la Cultura Conanoxa (IVIC-175: $3740 \pm 130$ años AP, $1790 \pm 130$ años AC).

Referencia bibliográfica: Schiappacasse y Niemeyer (1969 y Ms).

\section{Muestras 49, 50, 51, 52, 53}

Sitio: Abtao.

Ubicación: II región, península de Mejillones, costa norte del puerto de Antofagasta.

Tipo de sitio: Basural (montículo) de un área de campamentos abiertos.

Localización en el sitio: Muestras registradas de diversos niveles del depósito estratigráfico.

Subárea ecológica: Costa desértica de interfluvio.

Nombre del laboratorio: Instituto Venezolano de Investigaciones Científicas.

Colector de las muestras: G. Boisset y colaboradores (1969), Universidad del Norte.

Sigla y números del laboratorio: IVIC-679, 680, $681,682,683$.

Resultados recibidos: 4890 años AP.

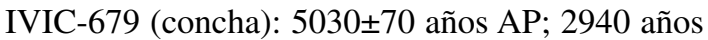
AC.

Sitio $\mathrm{N}^{\circ} 2$, pozo 2 (2.20 $\mathrm{cm}$ de profundidad).

IVIC-680 (concha): 4820 $\pm 70 ; 4960$ años AP, 3010 años AC. 
Sitio $\mathrm{N}^{\mathrm{o}} 2$, pozo 1 (2.40 $\mathrm{cm}$ de profundidad).

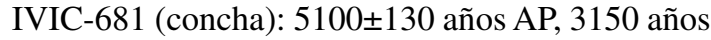
AC.

Sitio Abtao (montículo principal) a $0-10 \mathrm{~cm}$ de profundidad.

IVIC-682 (“carb. matl.”): 5090ะ180 años AP, 3140 años AC.

Sitio Abtao (montículo principal) a $90 \mathrm{~cm} \mathrm{de}$ profundidad.

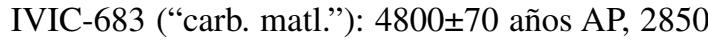
años AC.

Sitio Abtao (montículo principal) a $40 \mathrm{~cm} \mathrm{de}$ profundidad.

El Dr. Tamers del IVIC define la ocupación en Abtao en tres niveles radiocarbónicos:

Ocupación tardía: 4970 años AP, 3020 años AC.

Ocupación intermedia: 4870 años AP 2920 años AC.

Primera ocupación: 5170 años AP, 3220 años AC.

Contexto diagnóstico fechado: La homogeneidad de las fechas y el carácter conservador del yacimiento en términos de poca variabilidad tecnológica, presupone que los rasgos diagnósticos registrados pueden representar bien el rango de tiempo determinado. Entre estos rasgos se destacan doble-puntas, puntas de pedúnculo grande, posibles hojas taltaloides, pesas de concha para anzuelos compuestos y pesas específicas, anzuelos de concisa, anzuelos de hueso, anzuelos de cactus, barbas de hueso para arpones, textiles anudados, etc.

Comentario: La apreciación global de Boisset y colaboradores (1969: 111), antes de recibir la fechas, fue la siguiente: "[...] tal es que no se cumplen en este sitio las secuencias establecidas para las culturas precerámicas de la costa. Desde los primeros niveles de ocupación los pobladores ya están en posesión de todos los tipos de anzuelos [...]. El grueso de la cultura material se mantiene casi sin variaciones a través de todos los niveles de ocupación del sitio".
Abtao es un problema complicado. Bird (1943) y otros investigadores han preferido definir secuencias en yacimientos sin manteo monticulado. Si Abtao representa el patrón de adaptación en la costa de interfluvio al sur del Loa, debe ser reevaluado a la luz de un riguroso control microestratigráfico, al margen del uso de niveles convencionales de excavación. Esto permitirá evitar muestras contaminadas, como ocurrió con el registro que ofreció una determinación final levemente aberrante en la ocupación tardía. La muestra IVIC-680 del orden de 3010 años AC fue registrada a $2.40 \mathrm{~cm}$ de profundidad, lo cual supone una primera ocupación coherente. Sin embargo, las muestras IVIC-682 logradas a $90 \mathrm{~cm}$ ofrecen una datación algo más tardía de 3140 años AC. Por otra parte, la muestra IVIC-681 que procede del nivel 0-10 cm alcanza 3150 años AC. Es decir, entre el comienzo de la ocupación y el final median algo más de 100 años. Esta situación puede significar: 1) La formación monticular teóricamente presupone baja densidad de población que en no más de tres generaciones conformó el actual montículo; 2) Las muestras de conchas son aberrantes, por lo cual las dataciones IVIC-679 y 680, de la base de ocupación, darían resultados demasiado tardíos. Con este criterio IVIC-681, también de concha, debería ser tardía, pero Boisset (ponencia en el Congreso de Arqueología Chilena, Santiago) reconoció que existía una situación de inversión estratigráfica, de modo que es mejor invalidar esta determinación; 3) Las fechas IVIC-682-683 provienen, al parecer, de fibras vegetales y representarían dataciones coherentes, con una diferencia de 290 años, entre 50 $\mathrm{cm}$ de separación. Si el yacimiento originalmente alcanzó $3 \mathrm{~m}$ de altura, la velocidad de acumulación tentativa pudo ser de $50 \mathrm{~cm}$ : 100 años. El cálculo de 1800 a 2000 años de tiempo para la formación del montículo, contradice el estrecho rango de variación entre el comienzo y fin de ocupación, según las dataciones per se.

Aunque estos cálculos pueden cuestionarse, las fechas en conjunto sugieren un comienzo de ocupación definidamente posterior a Quiani Temprano ("Cultura del Anzuelo de Concha"). Su desarrollo parece representar un lapso de tiempo reducido entre 500 a 1000 años, cuando los componentes derivados del patrón Quiani Temprano se mezclan con ingredientes de la ocupación Anzuelo de Cactus. Esto ocurre en Quiani Tardío (3680 años AC), en donde también se presentan las "mezclas" de componentes como Abtao. 
Las observaciones de Boisset (1969) serían válidas si las fechas de Abtao hubieran alcanzado a los 4220 años AC del patrón Quiani I o Temprano. Las poblaciones que proliferan los primeros anzuelos de cactus, parecen ser parte del patrón Chinchorro Temprano. Las fechas entre Abtao y este patrón son coherentes y significarían un posible acomodo temporal de la distribución Chinchorro Temprano por la costa meridional.

Referencia bibliográfica: Boisset (1969).

\section{Muestra 54}

Sitio: Isla Grande (RAnL-215).

Ubicación: II región, río Salado, zona de confluencia con el río Loa.

Subárea ecológica: Aporte tributario al Loa Medio con recursos de vegas.

Tipo de sitio: Campamento abierto.

Localización en el sitio: Nivel 3.

Colector de la muestra: E. Lanning, Estación de campo (Calama), Universidad de Columbia.

Resultado recibido: 4130 años AC.

Contexto diagnóstico fechado: Conjunto lítico descrito por Lanning (1968), caracterizado por una industria de puntas pedunculadas y asociados, elaborados con técnica de retoque a presión. Hay morteros.

Comentario: Esta fecha determinaría el comienzo de la ocupación de un campamento descrito por Orellana (1965). Según Lanning (1968), se trata de un sitio con varios depósitos estratigráficos, muy potentes en restos de fauna, asociado a abundantes puntas de proyectil (especialización en prácticas de caza).

Referencia bibliográfica: Orellana (1965), Lanning (1968).

\section{Muestra 55}

Sitio: Tuina (RAnL-108).

Ubicación: II región, quebrada de Tuina orientada a la cuenca Brinkerhoff, al este de Calama.
Subárea ecológica: Quebrada con aportes a la zona de cuencas del área de Calama.

Tipo de sitio: Alero o pequeño abrigo en los cerros de Tuina.

Colector de la muestra: E. Lanning. Estación de campo (Calama), Universidad de Columbia.

Resultado calculado: Lanning (1968) sugirió una edad correlativa a Quiani, con una cifra aproximada de 3500 años AC.

Resultado recibido: $9080 \pm 170$ años AP, 7130 años AC.

Contexto diagnóstico fechado: Industria de talla bifacial con retoques a presión. Son características las puntas y cuchillos triangulares de bases rectas y redondeadas.

Comentario: Según Lanning (1968), se trata de una industria de puntas y raederas de basalto y felsita, aún no descrita. Estas evidencias corresponden a un sitio de ocupación temprano, ubicado muy cerca del salar de Talabre. La ausencia de componentes del patrón Talabre (bifaces) permite establecer tres situaciones quizás diferentes: 1) Sitio ocupacional que depende de las canteras de Talabre, en donde se refinan las preformas, en un tiempo temprano coherente, anterior a la expansión del patrón de sitios con molienda; 2) Sitio ocupacional con énfasis en la explotación de los recursos del drenaje y cerros de Tuina, en una fecha posterior al uso de la industria de Talabre; 3) Fecha tardía o alterada, asociada a una industria cuya tipología es coherente con la industria de puntas y cuchillos de Quiani, es decir, no superior a 4220 años AC.

Referencia bibliográfica: Lanning (1968).

\section{Muestra 56}

Sitio: Confluencia (RAnL-195).

Ubicación: II región, zona de confluencia entre los ríos Salado y Loa.

Subárea ecológica: Aporte tributario al Loa, con asociación a vegas.

Localización en el sitio: Cuadrícula 2, Estrato 3. 
Colector de la muestra: E. Lanning, Estación de campo (Calama), Universidad de Columbia.

Resultado recibido: 5880 \pm 130 años AP; 3930 años AC.

Contexto diagnóstico fechado: La muestra fecha una industria con retoques presionados caracterizada por formas de puntas pedunculadas con leve estrechez en las bases, hojas lanceoladas (puntas y cuchillos), pequeñas puntas lanceoladas y ovoidales, puntas y cuchillos triangulares de bases escotadas.

Comentario: Este contexto se corresponde con el mismo sitio excavado por Orellana (1965) bajo el nombre de Confluencia 2. Se trata de un campamento abierto con montículos de desperdicios asociados a puntas foliáceas o lanceoladas. La fecha se correlaciona al complejo Isla Grande, en términos de industrias y viviendas en depresión. No se registran componentes del patrón Chiu Chiu. La determinación asegura su carácter precomplejo Chiu Chiu.

Referencia bibliográfica: Orellana (1965), Lanning (1968).

\section{Muestras 57, 58, 59, 60, 61, 62}

Sitio: Zona de Chiu Chiu: RAnL-92, 140, 151, 133, 104 B y 64.

Ubicación: II región, localidad de Chiu Chiu (río Loa Medio), cerca de Calama.

Subárea ecológica: Valle del Loa Medio, con recursos de vegas.

Tipo de sitio: Campamentos abiertos.

Colector de la muestra: M. Druss, Universidad de Columbia.

Resultado calculado: 4500 a 2500 años AP, para el desarrollo del llamado Complejo Chiu Chiu (Lanning y Patterson 1967).

Contexto diagnóstico fechado: Conjuntos líticos de puntas lanceoladas, cuchillos bilaciales, puntas lanceoladas medianas, doble puntas simétricas, perforadores, buriles y otros componentes microlíticos. Patrón de asentamiento con habitaciones en depresiones.
Comentario: El primer contexto bien definido fue descrito por Gómez (1963). Lanning y Patterson (1967) y Lanning (1968) identificaron abundantes puntas lanceoladas con finos retoques presionados y una alta frecuencia de artefactos aquillados.

Los estudios sistemáticos de Druss (1972 Ms) han identificado cerca de 50 sitios de este complejo, con 14 a 18 fases, distribuidos en un ambiente mayor, por desplazamientos trashumánticos. Los sitios presentan depósitos estratigráficos con restos orgánicos: camélidos, lanas, roedores, aves, peces, etc.

Resultados recibidos:

RAnL-92 (Cuadrícula 2, Estrato 3-b): 2705 años AC.

RAnL-140 (Cuadrícula 2, Estrato 3): 2580 años AC.

RAnL-151: 2550 años AC.

RAnL-133 (Cuadrícula 2, Estrato 4): 2300 años AC.

RAnL-104-B (Cuadrícula 1, Estrato 5): 2060 años AC.

RAnL-64 (Cuadrícula 1, Estrato 2): 2165 años AC.

Addenda: "Tenemos seis fechas de $\mathrm{C}^{14}$, las cinco que usted tiene de una de nuestras últimas conversaciones en Chile, y una más. La nueva fecha viene del estrato 2, cuadrícula 1 del sitio RAnL-4A, en el borde del cementerio actual de Chiu Chiu. La fecha es de 2165 \pm 105 años AC (I-6741, Teledyne Isotopes). Además, tengo una secuencia bien detallada, de más de 14 fases para el Complejo. Según mi análisis, la zona entre Calama y Chiu Chiu era abandonada durante varios períodos entre 3000 a 2000 años AC. Uno de estos períodos era ca. 2250-2300 AC y 2200-2165 AC. Este período corresponde a un período bien seco en Santa Elena, Ecuador, según las investigaciones de los Dres. Lanning y Sarma.

El Prof. Sarma piensa que todos los Andes están en un gran sistema climático y por eso los períodos de sequía en Santa Elena deben ser acompañados por períodos de sequía en la zona de Calama-Chiu Chiu. Por eso, los períodos de pluviosidad deben tener más o menos las mismas fechas en Calama-Chiu Chiu y en Santa Elena. Con la secuencia detallada que tengo para el Complejo Chiu Chiu podemos fechar los sitios individuales del Complejo. Hay grupos de sitios entre 3000 y 2000 años AC y la secuencia nos 
muestra que había períodos de varios años entre 3000 y 2000 años AC cuando no había nadie en la zona de Calama-Chiu Chiu. También hay otros periodos en que la zona era relativamente bien ocupada. Uno de estos períodos era entre los 2200 o 2165 y 2000 años AC. En general, los períodos de mucha ocupación humana se corresponden con períodos de pluviosidad en Santa Elena y, por eso, según el Dr. Sarma, los períodos de pluviosidad son generales en los Andes de Calama-Chiu Chiu-San Pedro de Atacama. Los períodos de sequía en Santa Elena y, por eso también en Chile, están marcados por períodos de abandono, registrados en Calama-Chiu Chiu. Tenemos una idea sobre las relaciones ecológicas en la zona, y por eso podemos reconstruir una hipótesis sobre los efectos de la sequía y pluviosidad en relación a los animales, especialmente de la vicuña, guanaco, vizcachas y plantas. Esta hipótesis puede explicar el por qué los períodos de sequía deben ser etapas de abandono en la zona de Calama-Chiu Chiu, y por qué los períodos de pluviosidad deben ser etapas de ocupación intensiva por parte de cazadores y recolectores del complejo Chiu Chiu" (M. Druss com. pers. a G. Le Paige, 1973).

Referencias bibliográficas: Lanning y Patterson (1967), Druss (1972 Ms).

\section{Muestra 63-61}

Sitio: Solor 4.

Ubicación: II región, campo Solor a 6 km de San Pedro de Atacama.

Subárea ecológica: Oasis al pie de la Puna de Atacama.

Tipo de sitio: Cementerio.

Tipo de muestra: Madera (“doorheads”).

Localización en el sitio: "el sitio está cubierto por 1.70 de arena".

Colector de la muestra: J. Spinner (1961), Instituto de Arqueología, Universidad Católica de Valparaíso.

Sigla y número de laboratorio: Gr N-4124 (Atacama-1) Gr N-4125 (Atacama-2).
Resultado recibido: Gr N-4124 : 970 \pm 75 años AP, 980 años DC.

Gr N-4125 : 770 \pm 65 años AP, 1180 años DC.

Observaciones del laboratorio: "Sample Gr N-1124 practically all dissolved in dilute alkali, this alkalisoluble fraction was measu, red. As other sample gave even younger date, there is no reason to suspect date".

Contexto diagnóstico fechado: Ambas muestras fechan evidencias de la cerámica llamada "Roja violácea" o "concho de vino" (San Pedro Rojo Pintado), correspondiente a la fase cerámica inmediatamente preinca del Complejo Cultural San Pedro de Atacama.

Comentario: Ambas fechas son coherentes para determinar un tiempo de la última fase cerámica (tardía) de la secuencia de San Pedro de Atacama (G. Le Paige, com. pers.).

Referencia bibliográfica. Deevey y colaboradores (1967).

\section{Muestra 65}

Sitio: Quitor 5.

Ubicación: II región, oasis a pie de la Puna de Atacama, cercano a San Pedro de Atacama.

Subárea ecológica: Oasis del pie de la Puna de Atacama.

Tipo de sitio: Cementerio.

Localización en el sitio: Tumba 3397.

Colector de la muestra: G. Le Paige, Museo Arqueológico San Pedro de Atacama.

Sigla y número del laboratorio: I-1205.

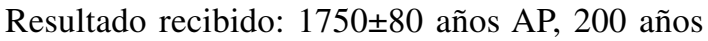
DC.

Contexto diagnóstico fechado: Cerámica San Pedro Rojo Pulido y Negro Pulido.

Referencia bibliográfica: G. Le Paige (com. pers.). 


\section{Muestra 66}

Sitio: Quitor 9.

Tipo de sitio: Cementerio.

Localización en el sitio: Tumba 3236.

Colector de la muestra: G. Le Paige, Museo Arqueológico San Pedro de Atacama.

Sigla y número del laboratorio: I-1205.

Resultado recibido: $900 \pm 80$ años AP, 1050 años DC.

Contexto diagnóstico fechado: Cerámica tardía del altiplano del tipo negro sobre blanco Huruquilla, asociada a cerámica Dupont con tratamiento negro engobado en su interior y keros-retratos de madera (tiwanacoides).

Referencia bibliográfica: G. Le Paige (com. pers.).

\section{Muestra 67}

Sitio: Toconao Oriente.

Ubicación: II región, oasis de Toconao, al sur de San Pedro de Atacama.

Subárea ecológica: Oasis del pie de la Puna de Atacama.

Tipo de sitio: Cementerio.

Tipo de muestra: Madera (fragmento de poste funerario y comida de algarrobo).

Localización en el sitio: Tumba 4340.

Nombre del laboratorio: Informe personal del Ing. Dr. Antonio Plata (Madrid).

Colector de la muestra: G. Le Paige, Museo Arqueológico de San Pedro de Atacama.

Resultado recibido: 2530 años AP, 580 años AC.

Contexto diagnóstico fechado: "Apogeo del tipo San Pedro Rojo Pulido y principio del tipo San Pedro Negro Pulido".
Comentario: Contexto funerario de una tumba de adulto, compuesto de una urna mediana del tipo común (fragmentada), siete tiestos de cerámica San Pedro Rojo Pulido (variedad de tipos), dos tiestos San Pedro Negro Pulido (un vaso cilíndrico con una asa y un puco hondo con fondo semiplano y dos asas laterales de promontorio), y tres bolas de comida de algarrobo.

Referencia bibliográfica: G. Le Paige (com. pers.).

\section{Muestra 68}

Sitio: Cueva de Tulan.

Ubicación: II región, quebrada de Tulan, en el borde sureste del Salar de Atacama.

Subárea ecológica: Quebrada de la vertiente occidental de la Puna de Atacama.

Tipo de sitio: Cueva.

Tipo de muestra: Carbón.

Localización en el sitio: Tercera capa (temprana).

Nombre del laboratorio: Informe personal del Ing. Dr. Antonio Plata (Madrid).

Colector de la muestra: G. Le Paige, Museo Arqueológico San Pedro de Atacama.

Resultado recibido: 3710 años AP, 1760 años AC.

Contexto diagnóstico fechado: Restos orgánicos de fibras vegetales, plumas de aves, huesos de camélidos y cerámica negra no pulida (cocina).

Comentario: La excavación de Le Paige se localizó cerca de la llamada "piedra del altar" en la cueva de Tulan. La primera capa fluctuó entre $0-15 \mathrm{~cm}$. La segunda entre 15 a $63 \mathrm{~cm}$, y la última o tercera varió entre 63 a 118, alcanzando la base estéril de la ocupación estratificada. La muestra representa bien el comienzo de la ocupación cerámica en la cueva de Tulan. Una evaluación estratigráfica de Tulan está en proceso de análisis como parte de nuestro programa de investigaciones. La muestra de Tulan recobrada por Spahny (ver muestra 17) se fechó en 770 años DC y representaría a uno de los estratos más tardíos de la misma cueva. 
Referencia bibliográfica: G. Le Paige (com. pers.).

\section{Muestra 69}

Sitio: Camino Chiu Chiu-Talabre.

Ubicación: II región, camino en el área de Chiu Chiu.
Resultado recibido: $1700 \pm 200$ años AP, 250 años DC.

Comentario: "Lamont al fin me hizo una fecha, ésta es para el antiguo sendero de llamas que va desde Chiu Chiu hasta el salar de Talabre, pasando por los sitios 5 (Vega Alta) y 6 (Loa). La fecha es de $1700 \pm 200$ años AP (250 años DC), o sea equivalente a Loa Tardío y San Pedro II" (E. Lanning com. pers. a G. Le Paige, 1970).

\begin{tabular}{|c|c|c|c|c|c|}
\hline Secuencia & $\begin{array}{c}\text { Altiplano } \\
\text { 4000-3500 m }\end{array}$ & $\begin{array}{c}\text { Puna-oasis y valles altos } \\
4000-2000 \mathrm{~m}\end{array}$ & $\begin{array}{c}\text { Valles-oasis } \\
\text { intermedios y bajos }\end{array}$ & Costa & Totales \\
\hline $1000-1500$ & & OOOO & OOOOOO & & 10 \\
\hline $500-1000$ & & OO & O O & OOO & 7 \\
\hline $0-500$ & & OOOOOO & OOO & $\mathrm{O}$ & 10 \\
\hline $0-1000$ & & O O & $\mathrm{O}$ & OOOOOO & 9 \\
\hline $1000-2000$ & & $\mathrm{O}$ & $\mathrm{OO}$ & $\mathrm{O}$ & 4 \\
\hline $2000-3000$ & & OOOOOO & OOOO & OOOOOO & 16 \\
\hline $3000-4000$ & & $\mathrm{O}$ & & 000000 & 7 \\
\hline $4000-5000$ & & $\mathrm{O}$ & OOO & $\mathrm{O}$ & 5 \\
\hline $5000-6000$ & & & & & 0 \\
\hline $6000-7000$ & & & & & 0 \\
\hline $7000-8000$ & & $\mathrm{O}$ & & & 1 \\
\hline $8000-9000$ & & $\mathrm{O}$ & & & 1 \\
\hline $9000-10000$ & & & & & 0 \\
\hline Totales & 0 & 25 & 21 & 24 & 70 \\
\hline
\end{tabular}

Cuadro 1. Distribución y frecuencia de las dataciones radiocarbónicas (70 muestras, sin considerar la addenda). 
REGISTRO REGIONAL DE FECHAS RADIOCARBONICAS DEL NORTE DE CHILE

\begin{tabular}{|c|c|c|c|}
\hline Sitios & \multicolumn{2}{|c|}{ Fechas $\mathrm{C}^{14}$} & Inferencia cultural \\
\hline San Lorenzo & $10280 \pm 120 \mathrm{AP}$ & $8330 \pm 120 \mathrm{AC}$ & Contexto desconocido \\
\hline Tuina (RAnL-108) & $9080 \pm 170$ AP & $7130 \pm 170 \mathrm{AC}$ & Complejo Precerámico \\
\hline Tarapacá 14A & $6830 \pm 270 \mathrm{AP}$ & $4880 \pm 270 \mathrm{AC}$ & Tarapacá Grupo I \\
\hline Tarapacá 14A & $6430 \pm 430 \mathrm{AP}$ & $4480 \pm 430 \mathrm{AC}$ & Tarapacá Grupo I \\
\hline Queani & $6170 \pm 220 \mathrm{AP}$ & $4220 \pm 220 \mathrm{AC}$ & Cultura Anzuelo de Concha Queani I \\
\hline Isla Grande (RAnL-215) & & $4130 \mathrm{AC}$ & Complejo Precerámico \\
\hline Tarapacá 2A & $5970 \pm 120$ AP & $4020 \pm 120 \mathrm{AC}$ & Tarapacá Grupo I \\
\hline Confluencia (RAnL-195) & $5880 \pm 130$ AP & $3930 \pm 130 \mathrm{AC}$ & Complejo Precerámico \\
\hline Queani & $5630 \pm 145 \mathrm{AP}$ & $3680 \pm 145 \mathrm{AC}$ & Final Cultura Anzuelo de Concha Queani II \\
\hline Abtao & $5100 \pm 130 \mathrm{AP}$ & $3150 \mathrm{AC}$ & Complejo Precerámico \\
\hline Abtao & $5090 \pm 180 \mathrm{AP}$ & $3140 \mathrm{AC}$ & Complejo Precerámico \\
\hline Pisagua Viejo 4 & $\begin{array}{l}5220 \pm 170 \text { AP } \\
4880 \pm 320 \text { AP }\end{array}$ & $\begin{array}{c}3050 \pm 245 \mathrm{AC} \\
\text { Promedio }\end{array}$ & Complejo Chinchorro \\
\hline Abtao & $4820 \pm 70 \mathrm{AP}$ & $3010 \mathrm{AC}$ & Complejo Precerámico \\
\hline Abtao & $5030 \pm 70 \mathrm{AP}$ & $2940 \mathrm{AC}$ & Complejo Precerámico \\
\hline Abtao & $4800 \pm 70 \mathrm{AP}$ & $2850 \mathrm{AC}$ & Complejo Precerámico \\
\hline Tarapacá 14A & $4780 \pm 130 \mathrm{AP}$ & $2830 \pm 130 \mathrm{AC}$ & Complejo Precerámico Tardío \\
\hline Caleta Huelén 42 & $4780 \pm 100 \mathrm{AP}$ & $2830 \pm 100 \mathrm{AC}$ & Complejo Huelén Temprano \\
\hline Tarapacá 12 & $4690 \pm 80 \mathrm{AP}$ & $2740 \pm 80 \mathrm{AC}$ & Complejo Precerámico Tardío \\
\hline Chiu Chiu & & $2705 \mathrm{AC}$ & Complejo Chiu Chiu \\
\hline Chiu Chiu & & $2580 \mathrm{AC}$ & Complejo Chiu Chiu \\
\hline Chiu Chiu & & $2300 \mathrm{AC}$ & Complejo Chiu Chiu \\
\hline Chiu Chiu & & $2165 \mathrm{AC}$ & Complejo Chiu Chiu \\
\hline Conanoxa W(a) & $4020 \pm 110 \mathrm{AP}$ & $2070 \pm 110 \mathrm{AC}$ & Cultura Conanoxa \\
\hline Chiu Chiu & & $2060 \mathrm{AC}$ & Complejo Chiu Chiu \\
\hline Conanoxa W(a) & $3970 \pm 120$ AP & $2020 \pm 120 \mathrm{AC}$ & Cultura Conanoxa \\
\hline Cáñamo 1 & $\begin{array}{c}3880 \pm 130 \text { AP } \\
4000 \pm 140 \text { AP }\end{array}$ & $\begin{array}{r}2010 \pm 136 \text { AC } \\
\text { Promedio }\end{array}$ & Complejo Cáñamo Temprano \\
\hline Tarapacá 18 & $3910 \pm 170$ AP & $1960 \pm 170 \mathrm{AC}$ & Complejo Precerámico Tardío \\
\hline Caleta Huelén 42 & $3780 \pm 90 \mathrm{AP}$ & $1830 \pm 90 \mathrm{AC}$ & Complejo Huelén Tardío \\
\hline Conanoxa W(a) & $3740 \pm 130 \mathrm{AP}$ & $1790 \pm 130 \mathrm{AC}$ & Cultura Conanoxa \\
\hline Tulan (cueva) & $3710 \mathrm{AP}$ & $1760 \mathrm{AC}$ & Complejo Cerámico Temprano \\
\hline Cáñamo 1 & $\begin{array}{l}2840 \pm 130 \text { AP } \\
2770 \pm 130 \text { AP }\end{array}$ & $\begin{array}{c}860 \pm 130 \mathrm{AC} \\
\text { Promedio dos fechas }\end{array}$ & Complejo Cerámico Cáñamo Tardío \\
\hline Toconao Oriente & $2530 \mathrm{AP}$ & $580 \mathrm{AC}$ & Complejo Cerámico Temprano, San Pedro I \\
\hline Caleta Huelén 43 & $2400 \pm 90 \mathrm{AP}$ & $450 \pm 90 \mathrm{AC}$ & Complejo Loa-túmulos (Cerámico Temprano) \\
\hline Caleta Huelén 10A & $2320 \pm 80 \mathrm{AP}$ & $370 \pm 80 \mathrm{AC}$ & Complejo Loa-túmulos (Cerámico Temprano) \\
\hline Conanoxa E (6) & $2270 \pm 70 \mathrm{AP}$ & $320 \pm 70 \mathrm{AC}$ & Complejo Conanoxa-túmulos (Cerámico Temprano) \\
\hline Chiu Chiu (RAnL-273/A1) & $2150 \pm 95 \mathrm{AP}$ & $200 \pm 95 \mathrm{AC}$ & Final Complejo Vega Alta (Cerámico Temprano) \\
\hline Caleta Huelén 7 & $2030 \pm 80 \mathrm{AP}$ & $80 \pm 80 \mathrm{AC}$ & Complejo Loa-túmulos (Cerámico Temprano) \\
\hline Caleta Huelén 10 & $2000 \pm 70 \mathrm{AP}$ & $50 \pm 70 \mathrm{AC}$ & Complejo Loa-túmulos (Cerámico Temprano) \\
\hline Chiu Chiu (RAnL-216) & $1935 \pm 110 \mathrm{AP}$ & $15 \pm 110 \mathrm{DC}$ & Complejo Vega Alta (Cerámico Temprano) \\
\hline Guatacondo 1 & $1890 \pm 90 \mathrm{AP}$ & $60 \pm 90 \mathrm{DC}$ & Guatacondo aldea temprana \\
\hline
\end{tabular}


LAUTARO NUÑEZ A.

\begin{tabular}{|c|c|c|c|}
\hline Sitios & \multicolumn{2}{|c|}{ Fechas $\mathrm{C}^{14}$} & Inferencia cultural \\
\hline Loa (RAnL-100) & $1845 \pm 105 \mathrm{AP}$ & $105 \pm 105 \mathrm{DC}$ & Complejo Loa Tardío \\
\hline Quitor 5 & $1750 \pm 80 \mathrm{AP}$ & $200 \mathrm{DC}$ & Complejo San Pedro I-II \\
\hline Caleta Huelén 10 & $1735 \pm 100 \mathrm{AP}$ & $215 \pm 100 \mathrm{DC}$ & Complejo Loa-túmulos (Cerámico Temprano) \\
\hline Ouitor 6 & $1700 \pm 150 \mathrm{AP}$ & $250 \pm 150 \mathrm{DC}$ & San Pedro II \\
\hline Camino Chiu Chiu & $1700 \pm 200 \mathrm{AP}$ & $250 \pm 200 \mathrm{DC}$ & Sendero de Llamas Chiu Chiu-Talabre \\
\hline Tarapacá 40A & $1660 \pm 90 \mathrm{AP}$ & $290 \pm 90 \mathrm{DC}$ & Complejo Tarapacá Temprano \\
\hline Solor 6 & $1650 \pm 150 \mathrm{AP}$ & $300 \pm 150 \mathrm{DC}$ & San Pedro II \\
\hline Tarapacá 40A & $1590 \pm 170 \mathrm{AP}$ & $360 \pm 170 \mathrm{DC}$ & Complejo Tarapacá Temprano \\
\hline Caleta Huelén 2 & $1425 \pm 80 \mathrm{AP}$ & $525 \pm 80 \mathrm{DC}$ & Complejo no definido \\
\hline Cáñamo 3 & $1190 \pm 60 \mathrm{AP}$ & $760 \pm 60 \mathrm{DC}$ & Complejo Patache \\
\hline Tulan (cueva) & $1180 \pm 60 \mathrm{AP}$ & $770 \pm 60 \mathrm{DC}$ & Contexto no definido \\
\hline Guatacondo 1 & $1175 \pm 90 \mathrm{AP}$ & $775 \pm 90 \mathrm{DC}$ & Guatacondo Aldea (reocupación no definida) \\
\hline Conanoxa E (1) & $1150 \pm 95 \mathrm{AP}$ & $800 \pm 95 \mathrm{DC}$ & Complejo Conanoxa-estructuras \\
\hline Caleta Huelén 43 & $1130 \pm 80 \mathrm{AP}$ & $820 \pm 80 \mathrm{DC}$ & Final Complejo Loa-túmulos \\
\hline Solor 4 & $970 \pm 75 \mathrm{AP}$ & $980 \pm 75 \mathrm{DC}$ & San Pedro III \\
\hline Pica 8 & $950 \pm 70 \mathrm{AP}$ & $1000 \pm 70 \mathrm{DC}$ & Complejo Pica-Tiwanaku \\
\hline Pica 8 & $930 \pm 90 \mathrm{AP}$ & $1020 \pm 90 \mathrm{DC}$ & Complejo Pica \\
\hline Quitor 9 & $900 \pm 80 \mathrm{AP}$ & $1050 \pm 80 \mathrm{DC}$ & San Pedro III (comienzo) \\
\hline Azapa 8 & $810 \pm 80 \mathrm{AP}$ & $1140 \pm 80 \mathrm{DC}$ & Complejo San Miguel Temprano \\
\hline Guatacondo 1 & $775 \pm 160 \mathrm{AP}$ & $1175 \pm 160 \mathrm{DC}$ & Guatacondo Aldea (reocupación no definida) \\
\hline Solor 4 & $770 \pm 65$ AP & $1180 \pm 65 \mathrm{DC}$ & San Pedro III \\
\hline Lasana (RAnL-337-1) & $700 \pm 90 \mathrm{AP}$ & $1250 \pm 90 \mathrm{DC}$ & Complejo Lasana \\
\hline Azapa 8 & $680 \pm 80 \mathrm{AP}$ & $1270 \pm 80 \mathrm{DC}$ & Complejo San Miguel \\
\hline Azapa 8 & $580 \pm 80 \mathrm{AP}$ & $1370 \pm 80 \mathrm{DC}$ & Complejo San Miguel \\
\hline Dupont 1 & $460 \pm 100 \mathrm{AP}$ & $1490 \pm 100 \mathrm{DC}$ & Complejo Dupont \\
\hline Pica 8 & $310 \pm 110 \mathrm{AP}$ & $1640 \pm 110 \mathrm{DC}$ & Complejo Pica (aberrante sin corrección) \\
\hline Azapa 8 & $280 \pm 80 \mathrm{AP}$ & $1670 \pm 80 \mathrm{DC}$ & Complejo San Miguel (aberrante sin corrección) \\
\hline Pica 8 & $220 \pm 80 \mathrm{AP}$ & $1730 \pm 80 \mathrm{DC}$ & Complejo Pica (aberrante sin corrección \\
\hline
\end{tabular}

Cuadro 2. Fechas radiocarbónicas del Norte Grande de Chile en orden cronológico (septiembre 1975). 


\section{Comentario}

Las fichas radiocarbónicas precedentes llevan una numeración de acuerdo al orden en que fueron dadas a conocer y representan diversos intereses por cronometrar determinados sitios arqueológicos. La lista, una vez ordenada en secuencia cronológica, permite balancear los avances y déficit que en cierta manera hacen más factible la construcción de un esquema de cronología absoluta. Sin embargo, al observar el esquema final adjunto, no se consideran algunas fases y complejos culturales, que aunque bien identificados arqueológicamente, no tienen una situación temporal definida $y$, por cierto, se han excluido del esquema. Por su parte, hemos reunido la totalidad de poblaciones con dataciones absolutas bajo nombres que no necesariamente deben aceptarse como sitios-tipos, o nominaciones culturales definitivas. En este esquema se consideran con nombres geográficos representativos a diversos sitios fechados que constituyen conjuntos de rasgos socioculturales diferenciados y que persisten con un carácter más o menos tradicional. Se trata más bien de diversos sitios-patrones, cuyos inventarios culturales están presentes en varias localidades, en lapsos de tiempos variables, de los cuales sólo conocemos determinadas fases. Por esta razón hemos dispuesto una secuencia en columnas independientes que se contactan e interdigitan plurilinealmente, a fin de evitar las tradicionales propuestas de secuencias rígidas unilineales (Cuadro 3).

A. Area de Valles y Costa: Incluye el conjunto de valles y quebradas entre Arica y Guatacondo y los segmentos de costa inmediata, que participan de un medio ecológico más o menos homogéneo, entre 0 a 2000 m.snm.

La fase Gentilar tiende a contactar con la ocupación inca, y se apoya en el momento mal conocido de la fase San Miguel. Su distribución es típica en el extremo norteño del área y se extiende por el litoral del área B. La fase San Miguel posee un amplio desarrollo post-Tiwanaku y en su base se intercala con ingredientes Tiwanaku Tardío (fase Pica-Tiwanaku). Su distribución simila la expansión Gentilar. Sincrónicamente al desarrollo San Miguel, hacia el sur del valle de Camarones, se conforman varias poblaciones tardías que constituyen el patrón Pica, el cual contacta con inca y en su base se mezcla con componentes Tiwanaku Tardío (Pica-Tiwanaku). Algunos componentes intrusivos como Maytas, Huruquilla, Chilpe, etc., se integran al patrón Pica
Tardío en donde predominan los tiestos Pica estriado, Chiza Modelado Tardío y San Miguel. En la fase Pica-Tiwanaku se identifica la cerámica Charcollo que basamenta el fuerte desarrollo tardío café-estriado con baños rojos, registrado posteriormente en el patrón Pica-Tardío.

Por el término Tiwanaku Tardío se reconocen a varias poblaciones que emergen después de la época clásica y que se responsabilizan de fundamentar el Desarrollo Regional con ingredientes altiplánicos y locales. Su efecto está implícito en la emergencia de los patrones San Miguel y Pica. Los aportes Tiwanaku Expansivo se mezclan con tradiciones locales y constituyen estilos zonales que anteceden y conviven con San Miguel: Maytas, Chiribaya, Sobraya, etc. Sin embargo, estos componentes variados y complejos colocados en el paquete Tiwanaku Tardío no tienen determinaciones específicas en su área de mayor distribución (valles de Arica y sur peruano).

Tiwanaku Temprano se compone de importantes contactos clásicos en los valles de Arica, y su punto inicial lo hemos inferido de las asociaciones entre la cerámica Negra Pulida de San Pedro de Atacama y sus indicadores clásicos datados con determinaciones más tempranas que lo presumido hasta ahora. En este lapso sobreviven varias poblaciones locales como Alto Ramírez, Tarapacá, Patache, Punta Blanca, etc., que interceptan la penetración de tiestos negrosrojos-grises pulidos de tradición Wankarani-San Pedro, y alternan con viejas tradiciones locales de tiestos caté-estriados o alisados, que parecen provenir de etapas más arcaicas. La mezcla de estos componentes con rasgos Tiwanaku está presente en el patrón Tarapacá Tardío y Alto Ramírez Tardío, que se colocan en un tiempo inmediatamente posterior a las fases tempranas compuestas de fechas coherentes. Incluye además al patrón Patache. No existen dataciones para el resto de los sitios de esta etapa crítica de cambios (proceso de agriculturación en vías de desarrollo). La caída de diversas oleadas de "enturbantados" en todas las ecologías favorables (enclaves) son partes de los primeros acomodos del poblamiento Tiwanaku, fuera de su ambiente orientealtiplano. Faltan dataciones interfases.

El patrón Caserones (aldea) se correlaciona con Tarapacá e integra tradiciones negro-rojo-gris pulidos con tiestos café-alisados, distribuidos en la costa del Loa, Patache (sur de Iquique) y en su propia zona de enterramientos de Tarapacá. Contacta con rasgos Negro Pulido Clásico y Tarapacá Café Alisado. Las 
dataciones tempranas de estas tradiciones pulidas en los oasis de Atacama y boca del Loa permiten aceptarlos como partes de un desarrollo temprano anterior a la expansión Tiwanaku. Las fechas de Tarapacá (enturbantados) fijan un tiempo acorde, pero su desarrollo tardío no está definido y puede alcanzar parte de Tiwanaku derivado.

Tarapacá Tardío es la zona de enterramientos más densa de la aldea Caserones y obviamente registra la misma tradición negro-rojo-gris pulidos mezclada con tiestos café-alisados y textiles Tiwanaku. Su desarrollo máximo puede inferirse de Patache, en donde se presenta el mismo tipo de asociación. La base de su desarrollo contacta con Tarapacá Temprano, que corresponde a la prolongación más arcaica del mismo yacimiento, con el comienzo de las mismas tradiciones, pero sin rasgos Tiwanaku. Este patrón (enturbantados) representa una población arcaica muy persistente entre los valles y costa desde Arica al Loa, compuesta por varias fases no fechadas. Las fechas de Tarapacá Temprano (Tr-40A) representarían un máximo desarrollo que tiende a contactar tardíamente con rasgos Tiwanaku. Esta población es similar al patrón Quitor, en términos de turbantes, tiestos pulidos y similares dataciones. Sin embargo, su base cronológica es incierta. Por ahora, la datación de Guatacondo (aldea) podría servir para fundamentar su desarrollo inicial (de acuerdo a la presencia de enterramientos similares junto a la aldea), pero su línea genética parece ser más temprana, derivada de las viejas tradiciones Chinchorro Tardío (mascarillas faciales con turbantes).

El patrón Alto Ramírez (Arica) se ha dispuesto sin dataciones radiocarbónicas, pero debe incluir un buen número de poblaciones de enturbantados de la zona de Arica que en su fase final se diluyen con rasgos Tiwanaku. En cierta medida participan del desarrollo Tarapacá Tardío, pero sus raíces pueden descender hasta una época sincrónica a las fechas de ConanoxaTúmulos. Es probable que Tarapacá y Alto Ramírez Tardío mantengan un desarrollo correlacionado a la secuencia establecida para Conanoxa-túmulos y Loa-túmulos, pero las dataciones de los túmulos de la boca del Loa y Camarones representan fases más tempranas que dificultan por ahora la postulación de una matriz cultural común.

Guatacondo ofrece un patrón peculiar derivado del viejo proceso aldeano Wankarani, eventualmente asociado a alguna fase temprana de enturbantados del patrón Tarapacá. Es probable que la determinación radiocarbónica corresponda al momento de mayor expansión del modelo aldeano, pero sus orígenes parecen ser más tempranos, toda vez que las fechas de Loa-túmulos confirman la existencia de ocupaciones precedentes con controles agropecuarios.

El patrón Conanoxa-túmulos es parte de la vieja tradición de poblaciones con enterramientos monticulados (costa del Loa) con una fecha correlacionada a la más temprana del Loa, la cual le sirve como base inicial. No obstante, este patrón es muy persistente y alcanza dilaciones más tardías no representadas en la zona Arica-Camarones.

Se aprecia en esta área una razonable coherencia en la secuencia de las ocupaciones con cerámica. Pero, hay un claro déficit de información bajo el paquete Tiwanaku Clásico. Por otra parte, los patrones locales Tarapacá, Alto Ramírez, Conanoxa y Loa-túmulos, deben ser tratados con mayor rigor cronológico. Precisamente en las bases de estos poblamientos deberían verse las relaciones con las derivaciones de las ocupaciones precerámicas. El ensamble a los patrones precerámicos Conanoxa y Chinchorro, si bien es intuido, no ha sido debidamente determinado.

El patrón Conanoxa parece persistir hasta épocas más tardías, pero sin duda es parte de un proceso de adaptación en valles a base del particular énfasis en prácticas de molienda. En este sentido, Conanoxa debe entenderse como una sobrevivencia de viejos patrones trashumánticos de molienda, asociados a anzuelos de concha, que incluyen variedades de maíces tempranos (patrón Tiliviche), actualmente en proceso de datación. Este proceso se ha identificado en la quebrada de Tarapacá con varias fechas agrupadas en secuencia. El patrón Tarapacá ejemplifica con sus dataciones más tempranas el comienzo (?) de las tradiciones de molienda especializada, que antecede a las fechas más tempranas de la costa. $\mathrm{Su}$ estadio de desarrollo simila al patrón Atacama de los ambientes del pie de la Puna (elementos de molienda).

El patrón Chinchorro Temprano es contemporáneo con Tarapacá y parece diluirse en las tradiciones Conanoxa, o de otro modo podría sobrevivir hasta la incorporación de los primeros brotes de horticultura más estable. Las dataciones Chinchorro (Pisagua Viejo) otorgan la base cronológica y su persistencia le permite intercalarse con Conanoxa y aun con la emergencia de las primeras poblaciones 
de enturbantados. Es sensible la falta de dataciones para sus etapas finales.

Quiani Tardío muestra un hito temporal muy cercano a Chinchorro Temprano y encierra el final de la tradición del anzuelo de concha. La fecha de Quiani Temprano parece señalar el comienzo de la ocupación Anzuelo de Concha en la costa. De lo anterior se desprende que aún restan dos situaciones cronológicas pendientes, por un lado el ambiente marítimo fue utilizado con anterioridad a Quiani Temprano, pero no se conocen evidencias de esta naturaleza. Por otra parte, las industrias líticas del pie de Puna de Atacama demuestran la existencia de sitios con remanentes premolienda. Hasta ahora no hay datos de esta naturaleza en la zona, a pesar de que los ambientes andinos de caza y recolección fueron altamente eficientes. Esto explica la ausencia de fechas precerámicas tempranas, que exigen una reevaluación adecuada.

B. Costa desértica de interfluvio: Se constituye por un extenso litoral marginado de las zonas de eficiencia de desembocaduras de ríos, desde el sur de Pisagua a Taltal. Es una región de máxima aridez, alterada por la mayor o menor frecuencia de zonas con vertientes y leves variaciones ambientales, con un denominador común: explotación marítima.

La explotación marítima excedentaria atrajo a diversas poblaciones procedentes de pisos agrarios. Los patrones San Miguel-Gentilar conviven con Pica Tardío, e interfieren por el río Loa diversas poblaciones Solor que integran a varios componentes tardíos (Dupont, San Pedro Rojo Violáceo, etc.) de amplia popularidad en la hoya del Loa y oasis de Atacama. La presencia del patrón Tarapacá y Alto Ramírez establece que aquí también existió un desarrollo de poblaciones tempranas que en su fase final contactan con Tiwanaku. El sitio Punta Blanca (cerca de Tocopilla) parece ser parte de este proceso. Sin embargo, sus componentes muestran la mezcla de dos tradiciones aparentemente distintas. Por un lado, la vieja tradición de tiestos café alisados emparentados con las fases El Laucho, Tarapacá y tiestos rojos pulidos del patrón Caserones y Patache, lo que en conjunto presupone la extensión de un temprano problamiento septentrional que limita en su fase final con Tiwanaku. Pero se suma un ingrediente distinto procedente de la hoya del Loa, derivado especialmente de los oasis de Atacama, a través de la incorporación de la tradición negro-café-gris pulido (vasos tubulares) que reflejan una mezcla cultural muy particular para los momentos inmediatamente pre-Tiwanaku, que aquí se enfatizan por el carácter marginal y receptivo del área. Creemos que estos patrones tempranos perduran en estos ambientes conservadores de caza-recolección hasta etapas más tardías que las registradas en áreas con regadío; sin embargo, el déficit de dataciones en esta área es muy significativa. También se difunde en este litoral el patrón Loa-túmulos sin fechas precisas.

La difusión del patrón Caserones y Patache demuestra los rápidos cambios que ocurren entre las poblaciones locales por el arribo de ingredientes agroculturales desde tierras altas. Este hecho se confirma con la presencia de componentes clásicos del patrón Quitor (San Pedro Negro Pulido), Toconao (transición San Pedro Rojo pulido y Negro Pulido) y aun de Larache (San Pedro Rojo Pulido), como partes de un viejo tráfico entre los centros agropecuarios interiores y la costa inmediata.

No está claro en qué momento las tradiciones precerámicas reciben los primeros contactos agrarios. Cáñamo Tardío demuestra una datación temprana aislada, sin consistencia para generalizar una situación similar en el resto del área. El patrón precerámico Cáñamo deriva de Chinchorro, como parte de la misma población, en sus fases tardías, pero en general su situación parece caracterizar un momento precerámico final entre Pisagua y la boca del Loa.

El proceso de cambios ocurrente entre las ocupaciones de cazadores-recolectores por la recepción de ingredientes agrarios no ha sido fechado y en este sentido el modelo de Cáñamo debería tener réplicas al sur (campamento Punta Blanca). Por ahora está claro que las principales ocupaciones precerámicas de este litoral están representadas por poblaciones Chinchorro y Quiani Tardío, como parte de ocupaciones homogéneas representadas en Abtao y Los Canastos. La persistencia de estos viejos patrones derivan de la ocupación Quiani Temprano (anzuelo de concha), pero su exacta supervivencia no ha sido delimitada convenientemente. El carácter conservador de esta área en términos de zonas óptimas de caza-recolección marítima presupone una larga persistencia de tradiciones no agriculturizadas, que pudieron convivir y sobrepasar a los enclaves con colonizaciones cerámicas tempranas.

El déficit de patrones con molienda (Conanoxa, Tarapacá, Atacama) se explica por la ausencia de ambientes fluviales. De este modo, la persistencia de 
Quiani y Caleta Huelén-Chinchorro parece reemplazar este vacío en términos ocupacionales. Es probable que los patrones de molienda hayan alcanzado el área pero sus campamentos debieron diferir radicalmente de sus hábitats internos. Aunque existe una leve distancia entre Quiani y Abtao-Chinchorro, es posible que ambos sean parte de una sola tradición que tiende a transformarse a través de la expansión Caleta Huelén-Chinchorro. La población de Caleta Huelén con rasgos físicos Chinchorro está bien datada y su disolución tardía parece intercalarse con poblaciones de enturbantados portadores de las primeras tradiciones cerámicas.

\section{Loa-Puna de Atacama: Se constituye por la} hoya del Loa y oasis-valles-cuencas de la Puna de Atacama. Aunque los diversos ecosistemas del Loa difieren de los pisos ambientados en la Puna, ambas entidades contiguas participan de tradiciones comunes, separadas por una cubierta estéril de las principales concentraciones de valles septentrionales.

En general, en las tierras altas entre Arica y el Loa (integran gran parte de las cabeceras de valles y altiplano) no presentan dataciones ni sitios regularmente documentados. Esta área, de contraparte, ofrece un buen número de hitos cronológicos.

El patrón Solor reúne a varios componentes tardíos debidamente fechados: Dupont, San Pedro Rojo Violáceo, Complejo Lasana y Huruquilla. Estas poblaciones son contemporáneas al patrón San Miguel-Pica. La presencia de tiestos Huruquilla y Dupont en la base del patrón Solor refleja una situación similar a la base del patrón Pica Tardío. Un componente Negro sobre Blanco con leve estilística Huruquilla asociado a rasgos tiahuanacoides actúa como base del patrón Solor.

Hay un déficit de dataciones entre el patrón Solor y los dispuestos en etapas más tempranas. Es posible que algunas fases intermedias como Coyo representada por San Pedro Negro Casi Pulido, sean nexos transitorios derivados de la vieja tradición San Pedro Negro Pulido. El patrón Coyo presenta componentes textiles Tiwanaku Tardío, asociados justamente a tiestos más tardíos provenientes de la tradición Negro Pulido.

El patrón Quitor ofrece el componente San Pedro Negro Pulido con dataciones que marcarían un punto inicial, asociado a ingredientes Tiwanaku Temprano. Es muy difícil presuponer sus antecedentes genéticos, los cuales habría que reconocerlos en la vieja tradición negra pulida de Wankarani. Tampoco tenemos dataciones para su supervivencia, que podría dar lugar a Coyo.

El patrón Toconao evidencia una situación transicional entre los componentes San Pedro Rojo Pulido y Negro Pulido, que por un largo tiempo coexistieron. El comienzo hipotético del componente exclusivo San Pedro Rojo Pulido, como un patrón diferenciado (Larache), está bien separado pero no fechado, con clara vinculación a Tiwanaku Clásico.

En esta área se intercalan dos poblaciones particulares, al parecer no correlacionadas con las fases tradicionales del Complejo San Pedro de Atacama. Se trata de los patrones Vega Alta y Loa Tardío, ubicados en la hoya media del Loa y que representan un desarrollo al parecer independiente, con dataciones tempranas bien calibradas. Por otra parte, el patrón Loa-túmulos de la zona de desembocadura marca una secuencia segura, de naturaleza temprana. La falta de sitios intermedios entre la costa y las tierras altas no esclarece correctamente su relación con las viejas ocupaciones de los patrones Toconao y Quitor. La presencia bilateral de tiestos con tratamientos pulimentados debería sugerir algún nivel de desarrollo común, pero por ahora esta cuestión está en debate. De uno u otro modo, el patrón Loa-túmulos proviene de tierras altas y su génesis hay que atribuirla a una temprana expansión agropecuaria estrechamente ligada a las viejas tradiciones monocromas pulimentadas de Wankarani y oasis de Atacama (túmulos funerarios de Solor: Negra Pulida Clásica).

Esta área también ofrece conjeturas cronológicas sobre el tránsito entre las ocupaciones cerámicas tempranas y el fin de los principales asentamientos precerámicos. El patrón Tulan-Cueva es una débil señal fechada de lo que podría ser el más temprano acontecimiento con cerámica inicial, en pleno ambiente alto, al pie de la Puna de Atacama. Pero, tampoco clarifica el contacto requerido para conocer el nexo entre el trabajo de caza-recolección andina y el comienzo agroganadero que actúa como estímulo temprano para la sedentarización cerámica "arcaica" en las tierras altas.

A pesar de los múltiples sitios con impresionantes industrias precerámicas, hay muy pocas dataciones absolutas que permitan la construcción de una secuencia razonable. Tres patrones precerámicos tardíos parecen ascender e intercalarse en el 
comienzo de las ocupaciones agropecuarias con cerámica temprana. El patrón Caleta HuelénChinchorro, en la desembocadura del Loa, ofrece una datación muy cercana al patrón Tulan-Cueva, es decir, se aproxima a un tiempo con cerámica inicial. Aunque ambas evidencias se extrapolan entre la costa y la puna, hay por lo menos una leve tendencia a que la vieja tradición Chinchorro, una vez que constituye sus centros aldeanos precerámicos, entra en un desarrollo ascendente, de manera que en su fase final pudo haber interceptado a los primeros cambios agropecuarios. El patrón Chiu Chiu es contemporáneo al anterior y demuestra un estadio de desarrollo cazador-recolector con énfasis en molienda, adaptado a ambientes fluviales y de vegas, con mejores posibilidades para subsistir en una etapa de cambios críticos por el ingreso del modelo agroganadero con cerámica temprana. Parece seguro que sus dataciones ejemplifican un patrón precerámico final con las últimas prácticas de molienda especializada, previa a la intensificación inicial del trabajo agropecuario.

No obstante, insistimos, no hay evidencia precisa para vislumbrar cómo estos patrones se diluyen entre poblaciones de túmulos, Toconao, Tarapacá, Alto Ramírez, etc. Las supervivencias tecnológicas existen, pero las inferencias cronológicas no son todavía confiables.

Existe en esta área una alta frecuencia de sitios con industrias y elementos de molienda (Tambillo, Puripica, etc.). Las fechas de Confluencia e Isla Grande dan dos hitos cronológicos sueltos, pero suficientes para aceptar que estos sitios son segmentos de un largo desarrollo de ocupaciones de caza-recolección andina y subandina que intensifican las prácticas de molienda. Es probable que sus vinculaciones con los patrones Tarapacá y Tiliviche sean satisfactorias. Este conjunto de sitios (no fechados) conforman el patrón Atacama. Esperamos un buen número de fechas para este estadio de desarrollo peculiar, por ahora su puesta en secuencia está avalada por el comienzo del Complejo Chiu Chiu, el comienzo temprano del patrón Tarapacá y dos fechas del Loa Medio.

En estas tierras altas se dispone de varios sitios con industrias de caza-recolección sin elementos de molienda. Siempre se presupone que sus dataciones deben ser más tempranas. En este sentido, el patrón Tuina nos señala una fecha muy tentativa para conjuntos líticos presumiblemente tempranos.

Finalmente, también aquí se han ubicado varias industrias líticas que por ofrecer morfologías burdas aparentemente podrían ser parte de patrones inmediatamente postpleistocénicos, aunque no deben excluirse los finos componentes paleoindianos. Ambas evidencias, en especial las industrias de percusión directa con retoques han estimulado una tendencia a disponer fases muy tempranas sin dataciones absolutas. La fecha de la cueva de San Lorenzo sólo nos sirve para presumir la presencia humana en etapas realmente tempranas, pero las identificaciones de indicadores culturales y paleoambientales está en proceso de investigación.

Al hacer un balance final, resulta complicado y pretencioso a la vez, establecer un esquema de secuencia "absoluta" para el norte de Chile. Deberemos orientar los surveys a etapas críticas sin información cronológica como ocurre entre 0 a 1000-2000 años $\mathrm{AC}$, en donde deben establecerse ocupaciones sensibles a fuertes cambios estructurales. Además, entre 3000 a 4000 años AC, prácticamente hay un vacío de dataciones. Bajo 5000 años AC la situación es francamente comprometedora. Si deseamos evaluar en términos realistas el comportamiento cronológico de la sociedad prehistórica regional y sus relaciones con las áreas aledañas, debemos aceptar que las indagaciones han sido lentas y deficientes. La elaboración de una secuencia más confiable en términos regionales exige de máximas prioridades. De lo contrario, estudiaremos hombres y acciones en abstracto. 
LAUTARO NUÑEZ A.

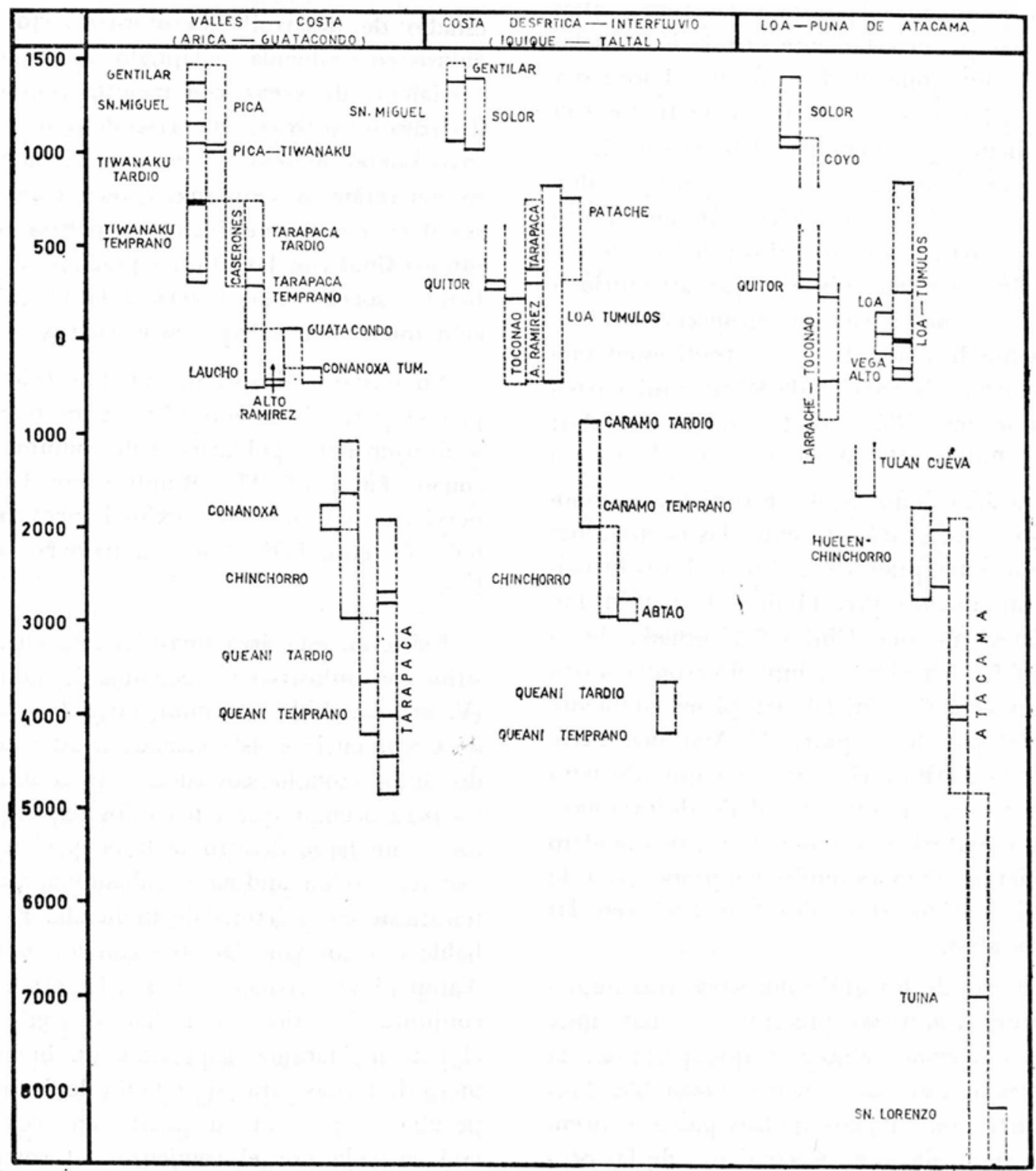

Cuadro 3. Esquema de cronología absoluta. 


\section{REFERENCIAS CITADAS}

ALVAREZ, L., 1969. Arqueología del departamento de Arica, secuencia cultural del Período Pre-Agroalfarero. Actas del Congreso Nacional de Arqueología, pp. 27-32. La Serena.

BIRD, J., 1945. Excavations in Northern Chile. Anthropological Papers of the American Museum of Natural History XXXVIII, part IV, pp. 171-316.

1946. The cultural secuence in the north Chilean coast. Handbook of South American Indians, vol. II, pp. 587-594. Smithsonian Institution Washington, Washington D.C.

1967. Muestras de radiocarbono de un basural precerámico de Quiani, Arica. Boletín 4: 13-14.

BOISSET, G., A. LLAGOSTERA y E. SALAS, 1969. Excavaciones arqueológicas en caleta Abtao, Antofagasta. Actas del Congreso Nacional de Arqueología, pp. 60-75. La Serena.

BOISSET, G. y A. LLAGOSTERA, Ms. Fechas radiocarbónicas de caleta Abtao, comparaciones con otras fechas de sitios costeros. Ponencia presentada en el Congreso Nacional de Arqueología Chilena, Santiago.

DAUELSBERG, P., 1963. Complejo arqueológico del Morro de Arica. Actas del Congreso Internacional de Arqueología en San Pedro de Atacama. Anales de la Universidad del Norte 2.

1972a. La cerámica de Arica y su situación cronológica. Chungara 1: 15-25.

1972b. Sobre la problemática de Arica, respuesta a L. Lumbreras. Chungara 1: 38-44.

-1972c. Arqueología del departamento de Arica. Apartado de la Enciclopedia de Arica, pp. 161-178.

DAUElsberG, P., L. AlVAREZ y S. CHACON, Ms. Investigaciones en torno a sitios-paraderos de cazadores tempranos. Ponencia presentada en el Congreso Nacional de Arqueología Chilena, Santiago.

ERICES, S. y G. FOCCACI, Ms. Los túmulos de San Miguel de Azapa. Ponencia presentada en el Congreso Nacional de Arqueología Chilena, Santiago.

GORDON, A., 1967. Fechas radiocarbónicas de la cronología arqueológica chilena. Boletín de Arqueología 4: 43-101.

LANNING, E. y T. PATTERSON, 1967. Early Man in South America. Scientific American 217 (5): 44-50.

LE PAIGE, G., 1963a. La antigüedad de una tumba comprobada por $\mathrm{C}^{14}$ y el ambiente que lo rodea. Revista de la Universidad Católica, año XLVIII: 167-176.

- 1963b. Continuidad y discontinuidad de la cultura atacameña. Congreso Internacional de Arqueología en San Pedro de Atacama. Anales de la Universidad del Norte 2: 7-25.

-1964. Los cementerios de la época agroalfarera en San Pedro de Atacama. Anales de la Universidad del Norte 3: 51-91.
LATCHAM, R., 1938. Arqueología de la región atacameña. Prensas de la Universidad de Chile, Santiago.

1941. Fases de la edad de la piedra en Chile. XXVII Congreso Internacional de Americanistas, pp. 257-265. Lima.

LUMBRERAS, L., 1972. Sobre la problemática arqueológica de Arica (carta a L. Núñez). Chungara 1: 27-29.

MEIGHAN, C., 1970. Excavations at Guatacondo, Chile, 1969. A preliminary report on the field activities of N.S.F. Grant G.S. 2652, Universidad de California, Los Angeles. Texto mimeografiado.

MELTZER, S., 1969. The salar de Talabre, Northern Chile... A tentative ecological reconstruction and a seriation of archaeological remains. Ponencia presentada en la Conference on Pleistocene Man in Latin America. San Pedro de Atacama. Texto mimeografiado.

MONTANE, J., 1972. Las evidencias del poblamiento temprano de Chile. Pumapunku 5: 40-53.

MOSTNY, G., 1964, Anzuelos de concha: 6170 más o menos 220 años. Noticiero Mensual del Museo Nacional de Historia Natural 9.

1965. Fechas radiocarbónicas de la quebrada de Guatacondo. Noticiero Mensual del Museo Nacional de Historia Natural 105.

NIEMEYER, H. y V. SCHIAPPACASSE, 1963. Investigaciones arqueológicas en las terrazas de Conanoxa, valle de Camarones (provincia de Tarapacá). Revista Universitaria XLVIII: 101-166.

NUÑEZ, L. y J. VARELA, 1961-64. Un complejo preagrícola en el salar del Soronal (cordillera de la costa). Revista del Instituto de Antropología de la Universidad Nacional de Córdoba II-III: 189-204.

1966. Complejo preagrícola en el salar del Huasco (provincia de Tarapacá). Estudios Arqueológicos 2: 9-24.

NUÑEZ, L., 1970. Algunos problemas del estudio del complejo Faldas del Morro, norte de Chile. Sonderdruck aus, ab handlungen und Benchte des staatlichen museums fur volkerkunde, pp. 79-109, Dresden, Band 31, AkademieVerlag, Berlin.

1971a. Primer fechado radiocarbónico del complejo Faldas del Morro en el sitio Tarapacá 40, y algunas consideraciones básicas. Actas del Congreso Nacional de Arqueología de La Serena, pp. 47-58. La Serena.

1971b. Secuencia y cambio de los asentamientos humanos de la desembocadura del río Loa, norte de Chile. Boletín de la Universidad de Chile 112: 3-25.

-1972a. Sobre el comienzo de la agricultura prehistórica en el norte de Chile. Pumapunku 4: 25-48. 
1972b. Sobre la problemática arqueológica de Arica, (respuesta a L. Lumbreras). Chungara 1: 30-37.

-Ms. Complejo Chinchorro en Pisagua Viejo. Apéndice de un estudio de J. Munizaga. En prensa.

— Ms-a. Dupont 1, un sitio tardío en el río Loa Medio.

-Ms-b. Asentamientos campesinos prehistóricos en los oasis de Pica (provincia de Tarapacá).

NUÑEZ, L., V. ZLATAR y P. NUÑEZ, Ms. Caleta Huelén 42: Una aldea temprana del norte de Chile. Ponencia presentada en el Congreso Nacional de Arqueología, Santiago.

-Ms-a. Secuencia de los asentamientos humanos en la costa de Cáñamo (provincia de Tarapacá).

NUÑEZ, L., C. MORAGAS y C. STAAL, Ms. Excavaciones en el sitio Tiliviche $1 \mathrm{~b}$ (provincia de Tarapacá).

NUÑEZ, P., Ms. Informe de recientes trabajos en Guatacondo.

NUÑEZ, P. y V. ZLATAR, Ms. Excavaciones en el sitio Aragón (provincia de Tarapacá).

ORELLANA, M., 1963. Problemas de la arqueología de San Pedro de Atacama y sus alrededores. Congreso Internacional de Arqueología San Pedro de Atacama, Anales de la Universidad del Norte 2: 29-45.

_ 1971. Informe de las excavaciones de Loa Oeste 3. Boletín de Prehistoria de Chile 4: 3-26.

ORELLANA, M., C. URREJOLA, C. THOMAS y G. SERRACINO, Ms. Uso del sistema de computación en los artefactos líticos del río Salado. Ponencia presentada en el Congreso Nacional de Arqueología, Santiago.

POLLARD, G., 1971. Cultural change and adaptation in the Central Atacama Desert of Northern Chile. Ñawpa Pacha 9: 41-64.
SERRACINO, G. y C. THOMAS, 1971. Excavación del yacimiento Confluencia 1. Boletín de Prehistoria 4: 49-63.

SCHIAPPACASSE, V. y H. NIEMEYER, 1969. Comentario a tres fechas radiocarbónicas de sitios arqueológicos de Conanoxa (valle de Camarones, prov. de Tarapacá). Noticiero Mensual del Museo Nacional de Historia Natural 151.

-Ms. Apuntes para el estudio de la trashumancia en el valle de Camarones (prov. de Tarapacá). Chile. Primer Congreso del Hombre Andino, Antofagasta.

SPAHNY, J. C., 1964. Le cemetière Atacaménien du Pucara de Lasana, vallée de rio Loa (Chile). Journal de la Société des Americanistes 53.

1967. Recherches archéologiques a l' embochoure du rio Loa (côte du Pacifique Chili). Journal de la Société des Americanistes, pp. 160-179.

_ 1967a. Comentario. Radiocarbón.

ESPOUEYS, O., Ms. Informe preliminar de dos fechados para Arica. Ponencia presentada en el Congreso Nacional de Arqueología, Santiago.

TRUE, D., L. NUÑEZ y P. NUÑEZ, 1970. Archaeological investigation in Northern Chile: Project Tarapacá. Preceramic resource. American Antiquity 35 (2): 170-184.

TRUE, D. y L. NUÑEZ, Ms. Un piso habitacional temprano en el norte de Chile.

TAMERS, M. A., 1965. Radiocarbón. Boletín del Laboratorio de Radiocarbón del Instituto Venezolano de Investigaciones Científicas.

UHLE, M., 1919. La arquelogía de Arica y Tacna. Boletín de la Sociedad Ecuatoriana de Estudios Históricos Americanos, Quito.

1992. Fundamentos étnicos y arqueología de Arica y Tacna. Boletín de la Sociedad Ecuatoriana de Estudios Históricos Americanos, Quito. 


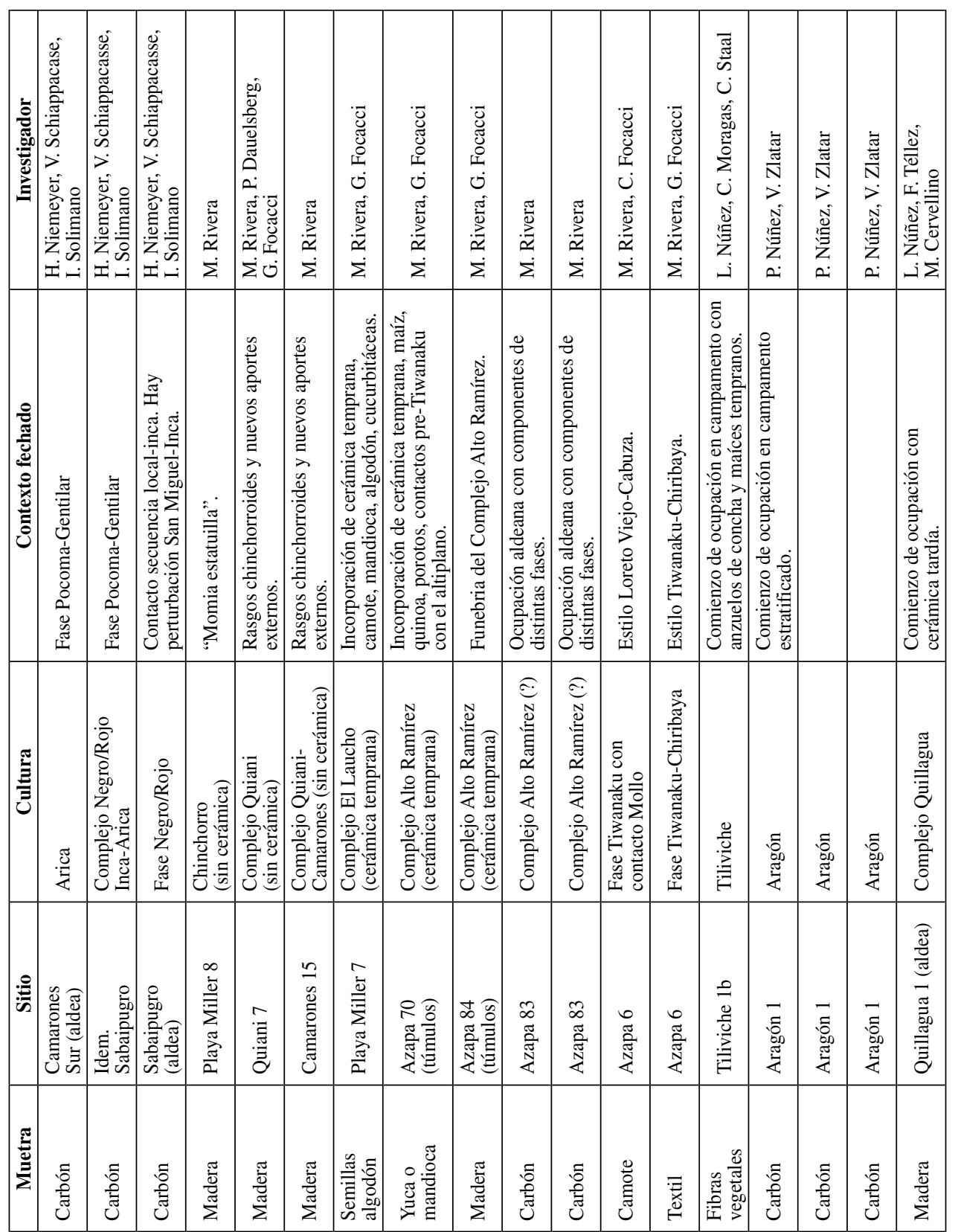

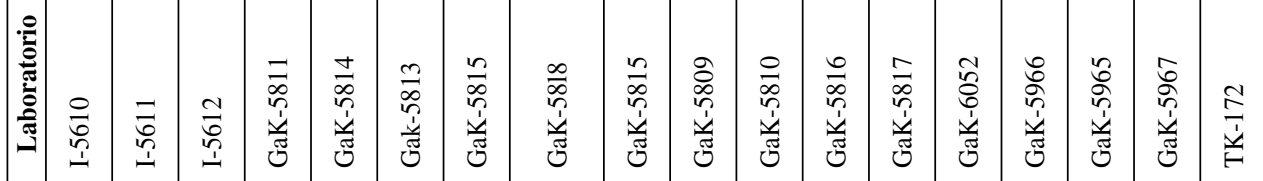

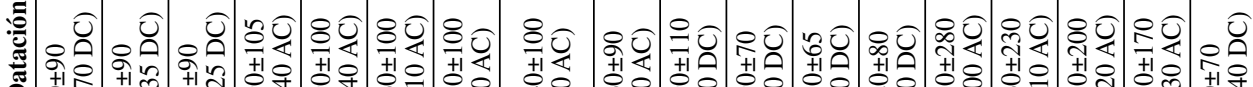

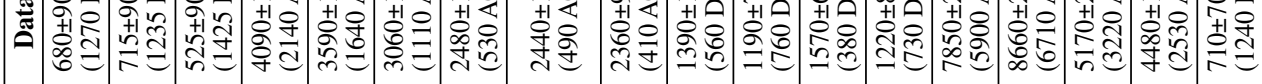

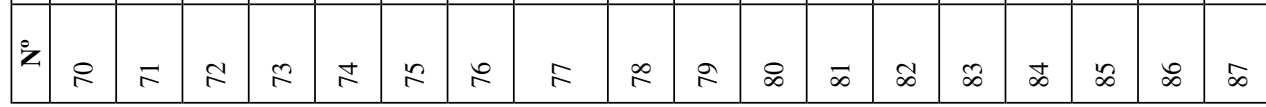

